\title{
Simultaneous iteration for variational inequalities over com- mon solutions for finite families of nonlinear problems
}

Lai-Jiu Lin

Department of Mathematics, National Changhua University of Education, Changhua, 50058, Taiwan.

Communicated by M. Bohner

\begin{abstract}
In this paper, we apply Theorem 3.2 of [G. M. Lee, L.-J. Lin, J. Nonlinear Convex Anal., 18 (2017), 1781-1800] to study the variational inequality over split equality fixed point problems for three finite families of strongly quasi-nonexpansive mappings. Then we use this result to study variational inequalities over split equality for three various finite families of nonlinear mappings. We give a unified method to study split equality for three various finite families of nonlinear problems. Our results contain many results on split equality fixed point problems and multiple sets split feasibility problems as special cases. Our results can treat large scale of nonlinear problems by group these problems into finite families of nonlinear problems, then we use simultaneous iteration to find the solutions of these problems. Our results will give a simple and quick method to study large scale of nonlinear problems and will have many applications to study large scale of nonlinear problems.
\end{abstract}

Keywords: Split equality fixed point problem, split fixed point problem, quasi-pseudocontractive mapping, demicontractive mapping, pseudo-contractive mapping.

2010 MSC: 47H06, 47H09, 47H10, 47J25, 65K15.

(C)2018 All rights reserved.

\section{Introduction}

Let $T: H_{1} \rightarrow H_{1}$, and let Fix $(T)=\left\{x \in H_{1}: x=T x\right\}$ denote the fixed point set of $T$. For each $i \in\{1,2,3\}$, let $H_{i}$ be a real Hilbert space. Let $C$ and $Q$ be nonempty closed convex subsets of $H_{1}$ and $H_{2}$, respectively and $A: H_{1} \rightarrow H_{2}$ be a bounded linear operator.

The split feasibility problem (SFP) in finite dimensional Hilbert spaces was first introduced by Censor and Elfving [6] for modeling inverse problems which arise from phase retrievals and in medical image reconstruction.

The split feasibility problem (SFP) is the problem:

Find $\bar{x} \in H_{1}$ such that $\bar{x} \in C$ and $A \bar{x} \in Q$.

Let $\mathrm{F}: \mathrm{C} \rightarrow \mathrm{H}_{1}$ be an operator. The variational inequality problem $\operatorname{VIP}(\mathrm{F}, \mathrm{C})$ is the following problem:

Find $\bar{x} \in \mathrm{C}$ such that $\langle\mathrm{F} \bar{x}, u-\bar{x}\rangle \geqslant 0$ for all $u \in C$.

Email address: maljlin@cc.ncue.edu.tw (Lai-Jiu Lin)

doi: $10.22436 /$ jnsa.011.03.08

Received: 2017-11-10 Revised: 2018-01-03 Accepted: 2018-01-11 
The solution set of the variational inequality problem is denoted by $\mathrm{VI}(\mathrm{F}, \mathrm{C})$. The variational inequality problem $\operatorname{VIP}(\mathbf{F}, \mathbf{C})$ has many applications in engineering, optimization, and signal recovery problem, see for example, Chuang et al. [11] and references therein.

Let $A: \mathrm{H}_{1} \rightarrow \mathrm{H}_{3}$, B : $\mathrm{H}_{2} \rightarrow \mathrm{H}_{3}$ be bounded linear operators, the split equality problem (SEFP) which was first introduced by Moudafi [18] is the problem:

$$
\text { Find } \bar{x} \in C, \bar{y} \in Q \text { such that } A \bar{x}=B \bar{y} \text {. }
$$

The split equality problem has many applications such as decomposition method for PDE, application in image science, game theory, and intensity-modulated radiation [18]. It is easy to see that when $\mathrm{B}=\mathrm{I}$, and $\mathrm{H}_{2}=\mathrm{H}_{3}$, then (SEFP) is reduced to (SFP). Moudafi [18] introduced an iteration process to establish a weak convergence theorem for split equality problem under suitable assumptions.

Let $\mathrm{T}: \mathrm{H}_{1} \rightarrow \mathrm{H}_{1}, \mathrm{~S}: \mathrm{H}_{2} \rightarrow \mathrm{H}_{2}$ be firmly quasi-nonexpansive mappings such that $\operatorname{Fix}(\mathrm{T}) \neq \emptyset, \operatorname{Fix}(\mathrm{S}) \neq \emptyset$, and let $A: \mathrm{H}_{1} \rightarrow \mathrm{H}_{3}, \mathrm{~B}: \mathrm{H}_{2} \rightarrow \mathrm{H}_{3}$ be bounded linear operators. Moudafi and AI-Shemas [19] introduced an iteration process and established a weak convergence theorem for split equality fixed point problem (SEFPP):

$$
\text { Find } \bar{x} \in \operatorname{Fix}(T), \bar{y} \in \operatorname{Fix}(S) \text { such that } A \bar{x}=B \bar{y} \text {. }
$$

When $\mathrm{B}=\mathrm{I}$, and $\mathrm{H}_{2}=\mathrm{H}_{3}$, then (SEFPP) is reduced to the split common fixed point problem (SCFPP) $[7,17]:$

Find $\bar{x} \in \mathrm{H}_{1}$ such that $\bar{x} \in \operatorname{Fix}(U)$ and $A \bar{x} \in \operatorname{Fix}(W)$.

Recently, many results on split equality fixed point problem have been found and one is referred to $[8,10,23,24,26,27]$ and references therein.

Recently, Lee and Lin [14], studied variational inequality problem over split equality fixed point sets of strongly quasi-nonexpansive mappings with applications to variational inequality problem over split equality fixed point for the same type of $\mathrm{m}$ nonlinear operators.

In this paper, we apply Lee and Lin [14, Theorem 3.2] to study the variational inequality over split equality fixed point problems for three finite families of strongly quasi-nonexpansive mappings. Then we use this result to study variational inequalities over split equality for three various finite families of nonlinear mappings. We give a unified method to study split equality for three various finite families of nonlinear problems. Our results contain many results on split equality fixed point problems and multiple sets split feasibility problems as special cases. Our results can treat large scale of nonlinear problems by group these problems into finite families of nonlinear problems, then we use simultaneous iteration to find the solutions of these problems. Our results will give a simple and quick method to study large scale of nonlinear problems and will have many applications to study large scale of nonlinear problems.

\section{Preliminaries}

For each $i \in\{1,2,3,4\}$, let $H_{i}$ be a (real) Hilbert space with inner products $\langle\cdot, \cdot\rangle$ and norms $\|\cdot\|$, and let $I_{i}: H_{i} \rightarrow H_{i}$ be the identity mapping on $H_{i}$. Let $\left\{x_{n}\right\}_{n \in \mathbb{N}}$ be a sequence in $H_{i}$ and $x \in H_{i}$, we denote the strongly convergence and the weak convergence of $\left\{x_{n}\right\}_{n \in \mathbb{N}}$ to $x \in H_{i}$ by $x_{n} \rightarrow x$ and $x_{n} \rightarrow x$, respectively. Throughout this paper, we use these notations unless specified otherwise. Let $C$ be a nonempty subset of a real Hilbert space $\mathrm{H}_{1}$, and let $\mathrm{T}: \mathrm{C} \rightarrow \mathrm{H}_{1}$. Then $\mathrm{T}$ is

(1) nonexpansive if $\|T x-T y\| \leqslant\|x-y\|$ for all $x, y \in C$;

(2) quasi-nonexpansive if $\operatorname{Fix}(T) \neq \emptyset$ and $\|T x-y\| \leqslant\|x-y\|$ for all $x \in C$ and for all $y \in \operatorname{Fix}(T)$;

(3) $\rho$-strongly quasi-nonexpansive (in short $\rho$ - SQNE), where $\rho \geqslant 0$, if $\operatorname{Fix}(T) \neq \emptyset$ and

$$
\|T x-y\|^{2} \leqslant\|x-y\|^{2}-\rho\|T x-x\|^{2}
$$

for all $x \in C, y \in \operatorname{Fix}(T)$; 
(4) monotone if $\langle x-y, T x-T y\rangle \geqslant 0$ for all $x, y \in C$;

(5) $\gamma$-strongly monotone if there exists $\gamma>0$ such that $\langle x-y, T x-T y\rangle \geqslant \gamma\|x-y\|^{2}$ for all $x, y \in C$;

(6) pseudocontractive if $\|T x-T y\|^{2} \leqslant\|x-y\|^{2}+\|x-T x-(y-T y)\|^{2}$ for all $x, y \in C$;

(7) $k$-demicontractive if $\operatorname{Fix}(T) \neq \emptyset$ and there exists $-\infty<k<1$ such that $\|T x-y\|^{2} \leqslant\|x-y\|^{2}+$ $k\|T x-x\|^{2}$ for all $x \in C$ and for all $y \in \operatorname{Fix}(T)$;

(8) $k$-strictly pseudononspreading [20] if there exists $k \in(0,1)$ such that $\|T x-T y\|^{2} \leqslant\|x-y\|^{2}+k \| x-$ $T x-(y-T y) \|^{2}+\langle x-T x, y-T y\rangle$ for all $x, y \in C$;

(9) firmly nonexpansive if $\|T x-T y\|^{2}+\left\|\left(I_{1}-T\right) x-\left(I_{1}-T\right) y\right\|^{2} \leqslant\|x-y\|^{2}$ for all $x, y \in C$;

(10) directed if $\operatorname{Fix}(T) \neq \emptyset$, and $\langle T x-y, T x-x\rangle \leqslant 0$ for all $x \in C$ and for all $y \in \operatorname{Fix}(T)$;

(11) demiclosed if for each sequence $\left\{x_{n}\right\}$ and $x$ in $C$ with $x_{n} \rightarrow x$ and (I-T) $x_{n} \rightarrow 0$ implies that $(\mathrm{I}-\mathrm{T}) \mathrm{x}=0$;

(12) $\alpha$-averaged if there exist $\alpha \in(0,1)$ and a nonexpansive mapping $S: C \rightarrow \mathrm{H}_{1}$ such that $\mathrm{T}=(1-\alpha) \mathrm{I}+$ $\alpha S$;

(13) hemicontinuous if, for all $x, y \in C$, the mapping $g:[0,1] \rightarrow H_{1}$, defined by $g(t)=T(t x+(1-t) y)$ is continuous with respect to weak topology on $\mathrm{H}_{1}$;

(14) quasi-pseudocontractive if $\operatorname{Fix}(T) \neq \emptyset$ and $\|T x-y\|^{2} \leqslant\|x-y\|^{2}+\|T x-x\|^{2}$ for all $x \in C$ and for all $y \in \operatorname{Fix}(T)$;

(15) $\alpha$-inverse-strongly monotone (in short $\alpha$-ism) if $\langle x-y, T x-T y\rangle \geqslant \alpha\|T x-T y\|^{2}$ for all $x, y \in C$ and $\alpha>0$.

Lemma 2.1 ([3]). Let $\mathrm{C}$ be a nonempty closed convex subset of a real Hilbert space $\mathrm{H}_{1}$. Let $\mathrm{T}: \mathrm{C} \rightarrow \mathrm{H}_{1}$ be a nonexpansive mapping, and let $\left\{x_{n}\right\}_{n \in \mathbb{N}}$ be a sequence in $C$. If $x_{n} \rightarrow w$ and $\lim _{n \rightarrow \infty}\left\|x_{n}-T x_{n}\right\|=0$, then $T w=w$.

Let $f: H_{1} \rightarrow(-\infty, \infty]$ be a proper, lower-semicontinuous, and convex function. Then the subdifferential $\partial f$ of $f$ is defined by

$$
\partial f(x)=\left\{u \in H_{1}: f(y) \geqslant f(x)+\langle y-x, u\rangle \text { for all } y \in H_{1}\right\} .
$$

Let $C$ be a nonempty closed convex subset of a real Hilbert space $H_{1}$. For each $x \in H_{1}$, there is a unique element $u \in C$ such that $u=\arg \min _{y \in C}\|x-y\|$. The mapping $P_{C}: H_{1} \rightarrow C$ which is defined by $P_{C} x=\arg \min _{y \in C}\|x-y\|$ for $x \in H_{1}$ is called the metric projection from $\mathrm{H}_{1}$ onto $C$.

Proposition 2.2 ([1]). Let $\mathrm{C}$ be a nonempty subset of a Hilbert space $\mathrm{H}_{1}$, and let $\mathrm{T}: \mathrm{C} \rightarrow \mathrm{H}_{1}$ be nonexpansive, and $\alpha \in(0,1)$. Then the following are equivalent:

(i) $\mathrm{T}$ is $\alpha$-averaged;

(ii) $(\forall x \in C)(\forall y \in C),\|T x-T y\|^{2} \leqslant\|x-y\|^{2}-\frac{1-\alpha}{\alpha}\left\|\left(I_{1}-T\right) x-\left(I_{1}-T\right) y\right\|^{2}$.

Lemma 2.3 ([15]). Let $\mathrm{T}: \mathrm{H}_{1} \rightarrow \mathrm{H}_{1}$ be a $\mathrm{k}$-demicontractive operator with $\mathrm{k}<1$. Denote $\mathrm{T}_{\lambda}=(1-\lambda) \mathrm{I}_{1}+\lambda \mathrm{T}$ for $\lambda \in(0,1-k)$. Then for any $x \in \mathrm{H}_{1}, z \in \operatorname{Fix}(\mathrm{T})$,

$$
\left\|\mathrm{T}_{\lambda} x-z\right\|^{2} \leqslant\|x-z\|^{2}-(1-k-\lambda)\left\|\mathrm{T}_{\lambda} x-x\right\|^{2} .
$$

Lemma 2.4 ([20]). Let $\mathrm{C}$ be a nonempty closed convex subset of $\mathrm{H}_{1}$ and $\mathrm{T}: \mathrm{C} \rightarrow \mathrm{C}$ be a k-strictly pseudononspreading mapping with $\operatorname{Fix}(\mathrm{T}) \neq \emptyset$. Set $\mathrm{T}_{\lambda}=\lambda \mathrm{I}_{1}+(1-\lambda) \mathrm{T}, \lambda \in[\mathrm{k}, 1)$. Then the following hold:

(i) $\operatorname{Fix}\left(T_{\lambda}\right)=\operatorname{Fix}(T)$;

(ii) $\mathrm{T}_{\lambda}$ is demiclosed;

(iii) $\left\|T_{\lambda} x-T_{\lambda} y\right\|^{2} \leqslant\|x-y\|^{2}+\frac{2}{1-\lambda}\left\langle x-T_{\lambda} x, y-T_{\lambda} y\right\rangle-(\lambda-k)\left\|x-T_{\lambda} x-\left(y-T_{\lambda} y\right)\right\|^{2}$.

The equilibrium problem (EP) [2] is the problem:

Find $z \in C$ such that $g(z, y) \geqslant 0$ for each $y \in C$, 
where $\mathrm{g}: \mathrm{C} \times \mathrm{C} \rightarrow \mathbb{R}$ is a bifunction. The solution set of equilibrium problem (EP) is denoted by $\operatorname{EP}(\mathrm{C}, \mathrm{g})$. We say that $g: C \times C \rightarrow \mathbb{R}$ satisfies the following conditions (A1)-(A4) if the following conditions hold:

(A1) $g(x, x)=0$ for each $x \in C$;

(A2) $g$ is monotone, i.e., $g(x, y)+g(y, x) \leqslant 0$ for any $x, y \in C$;

(A3) for each $x, y, z \in C$, limsup $g(t z+(1-t) x, y) \leqslant g(x, y)$;

$$
\mathrm{t} \downarrow 0
$$

(A4) for each $x \in C$, the scalar function $y \rightarrow g(x, y)$ is convex and lower semicontinuous.

Theorem 2.5 ([12]). Let $\mathrm{g}: \mathrm{C} \times \mathrm{C} \rightarrow \mathbb{R}$ be a bifunction which satisfies conditions (A1)-(A4). For $\mathrm{r}>0$, define $\mathrm{T}_{\mathrm{r}}^{\mathrm{g}}: \mathrm{H}_{1} \rightarrow \mathrm{C}$ by

$$
\mathrm{T}_{\mathrm{r}}^{\mathrm{g}} x=\left\{z \in \mathrm{C}: \mathrm{g}(z, y)+\frac{1}{\mathrm{r}}\langle\mathrm{y}-z, z-x\rangle \geqslant 0, \forall y \in \mathrm{C}\right\}
$$

for all $\mathrm{x} \in \mathrm{H}$. Then the following hold:

(i) $\mathrm{T}_{\mathrm{r}}^{\mathrm{g}}$ is single-valued;

(ii) $\mathrm{T}_{\mathrm{r}}^{\mathrm{g}}$ is firmly nonexpansive, that is, $\left\|\mathrm{T}_{\mathrm{r}}^{\mathrm{g}} \mathrm{x}-\mathrm{T}_{\mathrm{r}}^{\mathrm{g}} \mathrm{y}\right\|^{2} \leqslant\left\langle x-y, \mathrm{~T}_{\mathrm{r}}^{\mathrm{g}} x-\mathrm{T}_{\mathrm{r}}^{\mathrm{g}} \mathrm{y}\right\rangle$ for all $\mathrm{x}, \mathrm{y} \in \mathrm{H}$;

(iii) $\left\{x \in H: \mathrm{T}_{\mathrm{r}}^{\mathrm{g}} x=\mathrm{x}\right\}=\{x \in \mathrm{C}: \mathrm{g}(\mathrm{x}, \mathrm{y}) \geqslant 0, \forall y \in \mathrm{C}\}$;

(iv) $\{x \in C: g(x, y) \geqslant 0, \forall y \in C\}$ is a closed and convex subset of $C$.

Here, $T_{r}^{g}$ is called the resolvent of $g$ for $r>0$.

Theorem 2.6 ([14]). Let $\mathrm{M}: \mathrm{C} \rightarrow \mathrm{H}_{1}$ be a hemicontinuous and monotone mapping. Suppose that $\mathrm{M}$ is locally bounded on $\mathrm{C}$. Then, for $\mathrm{r}>0$ and $\mathrm{x} \in \mathrm{H}_{1}$, define $\mathrm{T}_{\mathrm{r}}: \mathrm{H}_{1} \rightarrow \mathrm{C}$ by

$$
\mathrm{T}_{\mathrm{r}} x=\left\{z \in \mathrm{C}:\langle\mathrm{y}-z, M z\rangle+\frac{1}{\mathrm{r}}\langle\mathrm{y}-z, z-x\rangle \geqslant 0, \forall y \in C\right\}
$$

for all $\mathrm{x} \in \mathrm{H}$. Then the following hold:

(i) $\mathrm{T}_{\mathrm{r}}$ is single-valued;

(ii) $\mathrm{T}_{\mathrm{r}}$ is firmly nonexpansive, that is, $\left\|\mathrm{T}_{\mathrm{r}} \mathrm{x}-\mathrm{T}_{\mathrm{r}} \mathrm{y}\right\|^{2} \leqslant\left\langle x-\mathrm{y}, \mathrm{T}_{\mathrm{r}} \mathrm{x}-\mathrm{T}_{\mathrm{r}} \mathrm{y}\right\rangle$ for all $\mathrm{x}, \mathrm{y} \in \mathrm{H}$;

(iii) $\left\{x \in \mathrm{H}: \mathrm{T}_{\mathrm{r}} \mathrm{x}=\mathrm{x}\right\}=\mathrm{VI}(\mathrm{M}, \mathrm{C})$;

(iv) $\operatorname{VI}(M, C)$ is a closed and convex subset of $\mathrm{C}$.

Theorem 2.7 ([14]). Let $\mathrm{T}: \mathrm{C} \rightarrow \mathrm{H}_{1}$ be a hemi-continuous and pseudocontractive mapping. Suppose that $\mathrm{T}$ is locally bounded on $\mathrm{C}$. Then, for each $\mathrm{r}>0$ and each $\mathrm{x} \in \mathrm{H}_{1}$, define $\mathrm{F}_{\mathrm{r}}: \mathrm{H}_{1} \rightarrow \mathrm{C}$ by

$$
\mathrm{F}_{\mathrm{r}} x=\left\{z \in \mathrm{C}:\langle\mathrm{y}-z, \mathrm{~T} z\rangle-\frac{1}{\mathrm{r}}\langle\mathrm{y}-z,(1+\mathrm{r}) z-x\rangle \leqslant 0, \forall \mathrm{y} \in \mathrm{C}\right\}
$$

for all $\mathrm{x} \in \mathrm{H}_{1}$. Then the following hold:

(i) $\mathrm{F}_{\mathrm{r}}$ is single-valued;

(ii) $\mathrm{F}_{\mathrm{r}}$ is firmly nonexpansive;

(iii) $\operatorname{Fix}\left(\mathrm{F}_{\mathrm{r}}\right)=\operatorname{Fix}(\mathrm{T})$;

(iv) $\operatorname{Fix}(\mathrm{T})$ is a closed and convex subset of $\mathrm{C}$.

Proposition 2.8 ([5]). Let $\mathrm{A}: \mathrm{H}_{1} \rightarrow \mathrm{H}_{2}$ be a bounded linear operator with $\|\mathrm{A}\|>0$ and $\mathrm{T}: \mathrm{H}_{2} \rightarrow \mathrm{H}_{2}$ be an operator satisfying $\mathrm{TA} w=\mathrm{A} w$ for some $w \in \mathrm{H}_{1}$. Further let $\mathrm{V}=\mathrm{I}_{1}-\frac{1}{\|\mathrm{~A}\|^{2}} A^{*}\left(\mathrm{I}_{2}-\mathrm{T}\right) \mathrm{A}$. If $\mathrm{T}$ is an $\alpha$-SQNE operator for some $\alpha \geqslant 0$, then

(i) $\operatorname{Fix}(V)=A^{-1} \operatorname{Fix}(T)$;

(ii) $V$ is $\alpha$-SQNE. 
If $T$ is demiclosed, then $\mathrm{V}$ is demiclosed.

Define $L=\{1,2, \ldots, m\}$ and $\triangle_{m}=\left\{\omega=\left(\omega_{1} . \omega_{2}, \ldots, \omega_{m}\right) \in \mathbb{R}^{m}, \omega_{i} \geqslant 0, i \in L\right.$, and $\left.\sum_{i=1}^{m} \omega_{i}=1\right\}$.

Proposition 2.9 ([5]). For each $\mathrm{i} \in \mathrm{L}$, let $\mathrm{S}_{\mathrm{i}}: \mathrm{H}_{1} \rightarrow \mathrm{H}_{1}$ be demiclosed and $\rho_{i}$-SQNE Suppose that $\bigcap_{i \in \mathrm{L}} \operatorname{Fix}\left(\mathrm{S}_{i}\right) \neq$ $\emptyset$. Let $\mathrm{S}=\sum_{i=1}^{m} \omega_{i} S_{i}$, where $\omega \in \triangle_{m}$. Then $S$ is a $\rho$-SQNE operator with $\rho=\sum_{i=1}^{m}\left(\frac{\omega_{i}}{\rho_{i}+1}\right)^{-1}-1$ and $S$ is demiclosed.

Proposition 2.10 ([1]). Let $C$ be a nonempty subset of $\mathrm{H}_{1}$, let $\left\{\mathrm{T}_{i}\right\}_{i \in \mathrm{I}}$ be a finite family of quasi-nonexpansive operators from $\mathrm{C}$ to $\mathrm{H}_{1}$ such that $\bigcap_{i \in \mathrm{I}} \operatorname{Fix}\left(\mathrm{T}_{i}\right) \neq \emptyset$, let $\left\{\omega_{i}: i \in \mathrm{I}\right\}$ be strict positive numbers such that $\sum_{i \in \mathrm{I}} \omega_{i}=$ 1. Then $\operatorname{Fix}\left(\sum_{i \in I} \omega_{i} T_{i}\right)=\bigcap_{i \in I} \operatorname{Fix}\left(T_{i}\right)$.

Lemma 2.11 ([9]). Let $\mathrm{T}: \mathrm{H}_{1} \rightarrow \mathrm{H}_{1}$ be a $\mathrm{L}_{1}$-Lipschitz continuous mapping with $\mathrm{L}_{1}>0$. Denote $\mathrm{K}=(1-\xi) \mathrm{I}_{1}+$ $\left.\xi \mathrm{T}(1-\eta) \mathrm{I}_{1}+\eta \mathrm{T}\right)$. If $0<\xi<\eta<\frac{1}{1+\sqrt{1+\mathrm{L}_{1}^{2}}}$, then

(i) $\operatorname{Fix}(\mathrm{T})=\operatorname{Fix}(\mathrm{K})$;

(ii) if $\mathrm{T}$ is demiclosed, then $\mathrm{K}$ is also demiclosed;

(iii) in addition, if $\mathrm{T}: \mathrm{H}_{1} \rightarrow \mathrm{H}_{1}$ is quasi-pseudocontractive, then $\mathrm{K}$ is quasi-nonexpansive.

Let $\mathrm{C}$ be a nonempty closed convex subset of $\mathrm{H}_{1}$, and let the indicate function $\iota_{C}: H_{1} \rightarrow[0, \infty]$ be defined by

$$
\mathrm{l}_{C} x= \begin{cases}0, & x \in C \\ \infty, & x \notin C .\end{cases}
$$

Then $\mathrm{I}_{\mathrm{C}}$ is a proper, lower semicontinuous, and convex function and $\mathrm{J}_{\lambda}^{\partial \mathrm{l}_{\mathrm{C}}}=\mathrm{P}_{\mathrm{C}}$.

Let $g \in \Gamma_{0}\left(H_{1}\right)$ and $\lambda \in(0, \infty)$. The proximal operator of $g \in \Gamma_{0}\left(H_{1}\right)$ of order $\lambda \in(0, \infty)$ is

$$
\operatorname{prox}_{\lambda g} x=\arg \min _{v \in H_{1}}\left\{g(v)+\frac{1}{2 \lambda}\|v-x\|^{2}\right\}, x \in H_{1} .
$$

Lemma 2.12 ([1]). Let $\mathrm{g} \in \Gamma_{0}\left(\mathrm{H}_{1}\right)$ and $\lambda \in(0, \infty)$. Then

(i) $\operatorname{prox}_{\lambda g}=\left(\mathrm{I}_{1}+\lambda \partial \mathrm{g}\right)^{-1}=\mathrm{J}_{\lambda}^{\partial g}$;

(ii) prox $_{\lambda g}$ is firmly nonexpansive;

(iii) if $\mathrm{C}$ is a nonempty closed convex subset of $\mathrm{H}_{1}$ and $\mathrm{g}=i_{\mathrm{C}}$, then prox $\lambda_{\lambda \mathrm{g}}=\mathrm{P}_{\mathrm{C}}$ for all $\lambda \in(0, \infty)$.

Lemma 2.13 ([16]). Let $\mathrm{C}$ be a nonempty closed convex subset of a real Hilbert space $H$, and let $\mathrm{T}: \mathrm{C} \rightarrow \mathrm{C}$ be $a \mathrm{k}-$ strictly pseudocontractive mapping. Then $\mathrm{T}$ is demiclosed.

\section{Variational inequalities over split equality fixed point for finite families of nonlinear mappings}

For each $i \in\{1,2,3,4\}$, let $H_{i}$ be a Hilbert space, $I_{i}$ be the identity mapping on $H_{i}, V_{i}: H_{i} \rightarrow H_{i}$ be $L_{i}$-Lipschitz continuous, $F_{i}: H_{i} \rightarrow H_{i}$ be $\kappa_{i}$-Lipschitz continuous and $\eta_{i}$-strongly monotone with $\kappa_{i}>0$, and $\eta_{i}>0$. Let

$$
L=\max _{i \leqslant i \leqslant 3} L_{i}, k=\max _{1 \leqslant i \leqslant 3} \kappa_{i}, \eta=\min _{1 \leqslant i \leqslant 3} \eta_{i}, \mu \in\left(0, \frac{2 \eta}{\kappa^{2}}\right) \text { and } \gamma \in\left(0, \frac{\tau}{L}\right),
$$

where $\tau=\mu\left(\eta-\frac{1}{2} \mu \kappa^{2}\right)$. For each $i \in\{1,2,3\}$, let $A_{i}: H_{i} \rightarrow H_{4}$ be a bounded linear operator with adjoint $A_{i}^{*}$. Suppose that $\left\|A_{i}\right\|>0,0<\xi<\frac{1}{\sum_{i=1}^{3}\left\|A_{i}\right\|^{2}}$. Let $B_{1}: H_{1} \rightarrow H_{2}$ be a bounded linear operator with adjoint $B_{1}^{*}$ and let $B_{2}: H_{1} \rightarrow H_{3}$ be a bounded linear operator with adjoint $B_{2}^{*}$. Suppose that $\left\|B_{1}\right\|>0$ and $\left\|B_{2}\right\|>0$. The product $\bigotimes_{1 \leqslant i \leqslant 3} H_{i}=H_{1} \times H_{2} \times H_{3}$ is a Hilbert space with inner product and norm given by

$$
\langle x, y\rangle=\sum_{i=1}^{3}\left\langle x_{i}, y_{i}\right\rangle \text { and }\|x\|^{2}=\sum_{i=1}^{3}\left\|x_{i}\right\|^{2}
$$


for any $x=\left(x_{1}, x_{2}, x_{3}\right), y=\left(y_{1}, y_{2}, y_{3}\right) \in \bigotimes_{1 \leqslant i \leqslant 3} H_{i}$. For any $x=\left(x_{1}, x_{2}, x_{3}\right) \in \bigotimes_{1 \leqslant i \leqslant 3} H_{i}$, let $V, F, I=$ $\mathrm{I}_{1} \times \mathrm{I}_{2} \times \mathrm{I}_{3}: \bigotimes_{1 \leqslant i \leqslant 3} \mathrm{H}_{\mathrm{i}} \rightarrow \bigotimes_{1 \leqslant i \leqslant 3} \mathrm{H}_{\mathrm{i}}$ be defined by

$$
\left\{\begin{array}{l}
I(x)=\left(x_{1}, x_{2}, x_{3}\right) \\
V(x)=\left(V_{1}\left(x_{1}\right), V_{2}\left(x_{2}\right), V_{3}\left(x_{3}\right)\right) \\
F(x)=\left(F_{1}\left(x_{1}\right), F_{2}\left(x_{2}\right), F_{3}\left(x_{3}\right)\right)
\end{array}\right.
$$

Let $\left\{\alpha_{n}\right\}_{n=0}^{\infty}$ be a sequence in $(0,1]$ such that $\lim _{n \rightarrow \infty} \alpha_{n}=0$, and $\sum_{n=1}^{\infty} \alpha_{n}=\infty$. In the following, we use these notations and assumptions unless specified otherwise.

Theorem 3.1 ([14]). For each $i \in\{1,2,3\}$, let $\rho_{i}>0$ and let $\mathrm{T}_{i}: \mathrm{H}_{i} \rightarrow \mathrm{H}_{i}$ be a demiclosed $\rho_{i}$-strongly quasinonexpansoive mapping. Suppose that

$$
\left.\Lambda=\left\{(x, y, z) \in \bigotimes_{1 \leqslant i \leqslant 3} H_{i}: x \in \operatorname{Fix}\left(T_{1}\right), y \in \operatorname{Fix}\left(T_{2}\right), z \in \operatorname{Fix}\left(T_{3}\right)\right), A_{1}(x)=A_{2}(y)=A_{3}(z)\right\} \neq \emptyset .
$$

Let $x_{1} \in H_{1}, y_{1} \in H_{2}, z_{1} \in H_{3}$, and let the sequences $\left\{\left(x_{n}, y_{n}, z_{n}\right)\right\}_{n} \in \mathbb{N}$ be defined by

(i) $x_{n+1}=\alpha_{n} \gamma V_{1}\left(x_{n}\right)+\left(I_{1}-\mu \alpha_{n} F_{1}\right) T_{1}\left(x_{n}-\frac{\xi}{3} A_{1}^{*}\left(2 A_{1}\left(x_{n}\right)-A_{2}\left(y_{n}\right)-A_{3}\left(z_{n}\right)\right)\right)$ for all $n \in \mathbb{N}$;

(ii) $y_{n+1}=\alpha_{n} \gamma V_{2}\left(y_{n}\right)+\left(I_{2}-\mu \alpha_{n} F_{2}\right) T_{2}\left(y_{n}-\frac{\xi}{3} A_{2}^{*}\left(2 A_{2}\left(y_{n}\right)-A_{1}\left(x_{n}\right)-A_{3}\left(z_{n}\right)\right)\right)$ for all $n \in \mathbb{N}$;

(iii) $z_{n+1}=\alpha_{n} \gamma V_{3}\left(z_{n}\right)+\left(I_{3}-\mu \alpha_{n} F_{3}\right) T_{3}\left(z_{n}-\frac{\xi}{3} A_{3}^{*}\left(2 A_{3}\left(z_{n}\right)-A_{1}\left(x_{n}\right)-A_{2}\left(y_{n}\right)\right)\right.$ for all $n \in \mathbb{N}$.

Then $\lim _{n \rightarrow \infty}\left(x_{n}, y_{n}, z_{n}\right) \in V I(\mu F-\gamma V, \Lambda)$.

Remark 3.2. The assumption " $\rho_{i}>0$ " is needed in [14, Theorem 3.2].

The following theorem and corollary are essential tools in this paper.

Theorem 3.3. For each $i \in\{1,2, \ldots, m\}, j \in\{1,2, \ldots, \ell\}, k \in\{1,2, \ldots, s\}$, let $\sigma_{i}>0, r_{j}>0$ and $\delta_{k}>0$, and let

(i) $\mathrm{M}_{i}: \mathrm{H}_{1} \rightarrow \mathrm{H}_{1}$ be a demiclosed $\sigma_{i}$-strongly quasi-nonexpansive mapping;

(ii) $\mathrm{Q}_{\mathrm{j}}: \mathrm{H}_{2} \rightarrow \mathrm{H}_{2}$ be a demiclosed $\mathrm{r}_{\mathrm{j}}$-strongly quasi-nonexpansive mapping;

(iii) $\mathrm{G}_{\mathrm{k}}: \mathrm{H}_{3} \rightarrow \mathrm{H}_{3}$ be a demiclosed $\delta_{\mathrm{k}}$-strongly quasi-nonexpansive mapping.

Let $\left(\zeta_{1}, \zeta_{2}, \ldots, \zeta_{\mathrm{m}}\right) \in \Delta_{\mathrm{m}},\left(\theta_{1}, \theta_{2}, \ldots, \theta_{\ell}\right) \in \Delta_{\ell},\left(\omega_{1}, \omega_{2}, \ldots, \omega_{\mathrm{s}}\right) \in \Delta_{s}$. Suppose that

$$
\Lambda=\left\{(x, y, z) \in \bigotimes_{1 \leqslant i \leqslant 3} H_{i}: x \in \bigcap_{i=1}^{m} \operatorname{Fix}\left(M_{i}\right), y \in \bigcap_{j=1}^{\ell} \operatorname{Fix}\left(Q_{j}\right), z \in \bigcap_{k=1}^{s} \operatorname{Fix}\left(G_{k}\right), A_{1}(x)=A_{2}(y)=A_{3}(z)\right\} \neq \emptyset .
$$

Let $x_{1} \in H_{1}, y_{1} \in H_{2}, z_{1} \in H_{3}$, and let the sequences $\left\{\left(x_{n}, y_{n}, z_{n}\right)\right\}_{n \in \mathbb{N}}$ be defined by

(i) $x_{n+1}=\alpha_{n} \gamma V_{1}\left(x_{n}\right)+\left(I_{1}-\mu \alpha_{n} F_{1}\right) \sum_{i=1}^{m} \zeta_{i} M_{i}\left(x_{n}-\frac{\xi}{3} A_{1}^{*}\left(2 A_{1}\left(x_{n}\right)-A_{2}\left(y_{n}\right)-A_{3}\left(z_{n}\right)\right)\right.$ for all $n \in \mathbb{N}$;

(ii) $y_{n+1}=\alpha_{n} \gamma V_{2}\left(y_{n}\right)+\left(I_{2}-\mu \alpha_{n} F_{2}\right) \sum_{j=1}^{\ell} \theta_{j} Q_{j}\left(y_{n}-\frac{\xi}{3} A_{2}^{*}\left(2 A_{2}\left(y_{n}\right)-A_{1}\left(x_{n}\right)-A_{3}\left(z_{n}\right)\right)\right)$ for all $n \in \mathbb{N}$;

(iii) $z_{n+1}=\alpha_{n} \gamma V_{3}\left(z_{n}\right)+\left(I_{3}-\mu \alpha_{n} F_{3}\right) \sum_{k=1}^{s} \omega_{k} G_{k}\left(z_{n}-\frac{\xi}{3} A_{3}^{*}\left(2 A_{3}\left(z_{n}\right)-A_{1}\left(x_{n}\right)-A_{2}\left(y_{n}\right)\right)\right)$ for all $n \in \mathbb{N}$.

Then $\lim _{n \rightarrow \infty}\left(x_{n}, y_{n}, z_{n}\right) \in V I(\mu F-\gamma V, \Lambda)$.

Proof. Let

(i) $\mathrm{T}_{1}=\sum_{\mathrm{i}=1}^{\mathrm{m}} \zeta_{\mathrm{i}} M_{i}$;

(ii) $T_{2}=\sum_{j=1}^{\ell} \theta_{j} Q_{j}$;

(iii) $T_{3}=\sum_{k=1}^{s} \omega_{k} G_{k}$.

By Proposition 2.9,

(i) $T_{1}$ is a demiclosed $\rho_{1}$-strongly quasi-nonexpansive mapping for some $\rho_{1}>0$; 
(ii) $T_{2}$ is a demiclosed $\rho_{2}$-strongly quasi-nonexpansive mapping for some $\rho_{2}>0$;

(iii) $T_{3}$ is a demiclosed $\rho_{3}$-strongly quasi-nonexpansive mapping for some $\rho_{3}>0$.

By Proposition 2.10,

(i) $\operatorname{Fix}\left(T_{1}\right)=\bigcap_{i=1}^{m} \operatorname{Fix}\left(M_{i}\right)$;

(ii) $\operatorname{Fix}\left(T_{2}\right)=\bigcap_{j=1}^{\ell} \operatorname{Fix}\left(Q_{j}\right)$;

(iii) $\operatorname{Fix}\left(T_{3}\right)=\bigcap_{k=1}^{s} \operatorname{Fix}\left(G_{k}\right)$.

Let $\left.\Omega=\left\{(x, y, z) \in \bigotimes_{1 \leqslant i \leqslant 3} H_{i}: x \in \operatorname{Fix}\left(T_{1}\right), y \in \operatorname{Fix}\left(T_{2}\right), z \in \operatorname{Fix}\left(T_{3}\right)\right), A_{1}(x)=A_{2}(y)=A_{3}(z)\right\}$.

It is easy to see that $\Omega=\Lambda \neq \emptyset$. Then Theorem 3.3 follows from Theorem 3.1.

Corollary 3.4. For each $\mathrm{i} \in\{1,2,3$, $\}$, let $\mathrm{V}_{\mathrm{i}}: \mathrm{H}_{1} \rightarrow \mathrm{H}_{1}$ be $\mathrm{L}_{\mathrm{i}}$-Lipschitz continuous, $\mathrm{F}_{\mathrm{i}}: \mathrm{H}_{1} \rightarrow \mathrm{H}_{1}$ be $\mathrm{\kappa}_{\mathrm{i}}$-Lipschitz continuous and $\eta_{i}$-strongly monotone with $\mathrm{K}_{i}>0$, and $\eta_{i}>0$.

For each $i \in\{1,2, \ldots, m\}, j \in\{1,2, \ldots, \ell\}, k \in\{1,2, \ldots, s\}$, let $\sigma_{i}>0, r_{j}>0$ and $\delta_{k}>0$, and let

(i) $\mathrm{M}_{i}: \mathrm{H}_{1} \rightarrow \mathrm{H}_{1}$ be a demiclosed $\sigma_{i}$-strongly quasi-nonexpansive mapping;

(ii) $\mathrm{Q}_{\mathrm{j}}: \mathrm{H}_{1} \rightarrow \mathrm{H}_{1}$ be a demiclosed $\mathrm{r}_{\mathrm{j}}$-strongly quasi-nonexpansive mapping;

(iii) $\mathrm{G}_{\mathrm{k}}: \mathrm{H}_{1} \rightarrow \mathrm{H}_{1}$ be a demiclosed $\delta_{\mathrm{k}}$-strongly quasi-nonexpansive mapping.

Let $\left(\zeta_{1}, \zeta_{2}, \ldots, \zeta_{m}\right) \in \Delta_{m},\left(\theta_{1}, \theta_{2}, \ldots, \theta_{\ell}\right) \in \Delta_{\ell},\left(\omega_{1}, \omega_{2}, \ldots, \omega_{s}\right) \in \Delta_{s}$. Suppose that

$$
\Lambda=\left\{(x, x, x): x \in H_{1}, x \in \bigcap_{i=1}^{m} \operatorname{Fix}\left(M_{i}\right) \bigcap \bigcap_{j=1}^{\ell} \operatorname{Fix}\left(Q_{j}\right) \bigcap \bigcap_{k=1}^{s} \operatorname{Fix}\left(G_{k}\right)\right\} \neq \emptyset .
$$

Let $x_{1} \in \mathrm{H}_{1}, \mathrm{y}_{1} \in \mathrm{H}_{1}, z_{1} \in \mathrm{H}_{1}$, and let the sequences $\left\{\left(x_{\mathfrak{n}}, y_{n}, z_{\mathfrak{n}}\right)\right\}_{\mathfrak{n} \in \mathbb{N}}$ be defined by

(i) $x_{n+1}=\alpha_{n} \gamma V_{1}\left(x_{n}\right)+\left(I_{1}-\mu \alpha_{n} F_{1}\right) \sum_{i=1}^{m} \zeta_{i} M_{i}\left(x_{n}-\frac{\xi}{3}\left(2 x_{n}-y_{n}-z_{n}\right)\right)$ for all $n \in \mathbb{N}$;

(ii) $y_{n+1}=\alpha_{n} \gamma V_{2}\left(y_{n}\right)+\left(I_{1}-\mu \alpha_{n} F_{2}\right) \sum_{j=1}^{\ell} \theta_{j} Q_{j}\left(y_{n}-\frac{\xi}{3}\left(2 y_{n}-x_{n}-z_{n}\right)\right)$ for all $n \in \mathbb{N}$;

(iii) $z_{n+1}=\alpha_{n} \gamma V_{3}\left(z_{n}\right)+\left(I_{1}-\mu \alpha_{n} F_{3}\right) \sum_{k=1}^{s} \omega_{k} G_{k}\left(z_{n}-\frac{\xi}{3}\left(2 z_{n}-x_{n}-y_{n}\right)\right)$ for all $n \in \mathbb{N}$.

Then $\lim _{n \rightarrow \infty}\left(x_{n}, y_{n}, z_{n}\right) \in V I(\mu F-\gamma V, \Lambda)$.

Proof. Let $H_{1}=H_{2}=H_{3}=H_{4}, A_{1}=I_{1}=A_{2}=A_{3}$ in Theorem 3.3, then Corollary 3.4 follows from Theorem 3.3.

Theorem 3.5. For each $i \in\{1,2, \ldots, m\}, j \in\{1,2, \ldots, \ell\}, k \in\{1,2, \ldots, s\}$, let

(i) $\mathrm{M}_{\mathrm{i}}: \mathrm{H}_{1} \rightarrow \mathrm{H}_{1}$ be a demiclosed $\sigma_{i}$-demicontractive mapping;

(ii) $\mathrm{Q}_{\mathrm{j}}: \mathrm{H}_{2} \rightarrow \mathrm{H}_{2}$ be a demiclosed $\mathrm{r}_{\mathrm{j}}$-demicontractive mapping;

(iii) $\mathrm{G}_{\mathrm{k}}: \mathrm{H}_{3} \rightarrow \mathrm{H}_{3}$ be a demiclosed $\delta_{\mathrm{k}}$-demicontractive mapping.

Let

(i) $M_{i} \lambda_{i}=\left(1-\lambda_{i}\right) I_{1}+\lambda_{i} M_{i}$ for $\lambda_{i} \in\left(0,1-\sigma_{1}\right)$;

(ii) $Q_{j} \beta_{j}=\left(1-\beta_{j}\right) I_{2}+\beta_{j} Q_{j}$ for $\beta_{j} \in\left(0,1-r_{j}\right)$;

(iii) $G_{k \eta_{k}}=\left(1-\eta_{k}\right) I_{3}+\eta_{k} G_{k}$ for $\eta_{k} \in\left(0,1-\delta_{k}\right)$.

Let $\left(\zeta_{1}, \zeta_{2}, \ldots, \zeta_{m}\right) \in \Delta_{m},\left(\theta_{1}, \theta_{2}, \ldots, \theta_{\ell}\right) \in \Delta_{\ell},\left(\omega_{1}, \omega_{2}, \ldots, \omega_{s}\right) \in \Delta_{s}$. Suppose that $\Lambda=\left\{(x, y, z) \in \bigotimes_{1 \leqslant i \leqslant 3} H_{i}\right.$ : $\left.x \in \bigcap_{i=1}^{m} \operatorname{Fix}\left(M_{i}\right), y \in \bigcap_{j=1}^{\ell} \operatorname{Fix}\left(Q_{j}\right), z \in \bigcap_{k=1}^{s} \operatorname{Fix}\left(G_{k}\right), A_{1}(x)=A_{2}(y)=A_{3}(z)\right\} \neq \emptyset$.

Let $x_{1} \in H_{1}, y_{1} \in H_{2}, z_{1} \in H_{3}$, and let the sequences $\left\{\left(x_{n}, y_{n}, z_{n}\right)\right\}_{n} \in \mathbb{N}$ be defined by

(i) $x_{n+1}=\alpha_{n} \gamma V_{1}\left(x_{n}\right)+\left(I_{1}-\mu \alpha_{n} F_{1}\right) \sum_{i=1}^{m} \zeta_{i} M_{i \lambda_{i}}\left(x_{n}-\frac{\xi}{3} A_{1}^{*}\left(2 A_{1}\left(x_{n}\right)-A_{2}\left(y_{n}\right)-A_{3}\left(z_{n}\right)\right)\right.$ for all $n \in \mathbb{N}$;

(ii) $y_{n+1}=\alpha_{n} \gamma V_{2}\left(y_{n}\right)+\left(I_{2}-\mu \alpha_{n} F_{2}\right) \sum_{j=1}^{\ell} \theta_{j} Q_{j} \beta_{j}\left(y_{n}-\frac{\xi}{3} A_{2}^{*}\left(2 A_{2}\left(y_{n}\right)-A_{1}\left(x_{n}\right)-A_{3}\left(z_{n}\right)\right)\right)$ for all $n \in \mathbb{N}$; 
(iii) $z_{n+1}=\alpha_{n} \gamma V_{3}\left(z_{n}\right)+\left(I_{3}-\mu \alpha_{n} F_{3}\right) \sum_{k=1}^{s} \omega_{k} G_{k \eta_{k}}\left(z_{n}-\frac{\xi}{3} A_{3}^{*}\left(2 A_{3}\left(z_{n}\right)-A_{1}\left(x_{n}\right)-A_{2}\left(y_{n}\right)\right)\right)$ for all $n \in$ $\mathbb{N}$.

Then $\lim _{n \rightarrow \infty}\left(x_{n}, y_{n}, z_{n}\right) \in V I(\mu F-\gamma V, \Lambda)$.

Proof. Since for each $i \in\{1,2, \ldots, m, j \in\{1,2, \ldots, \ell\}, k \in\{1,2, \ldots, s\}$,

(i) $M_{i}: H_{1} \rightarrow H_{1}$ be a demiclosed $\sigma_{i}$-demicontractive mapping;

(ii) $\mathrm{Q}_{\mathrm{j}}: \mathrm{H}_{2} \rightarrow \mathrm{H}_{2}$ be a demiclosed $\mathrm{r}_{\mathrm{j}}$-demicontractive mapping;

(iii) $\mathrm{G}_{\mathrm{k}}: \mathrm{H}_{3} \rightarrow \mathrm{H}_{3}$ be a demiclosed $\delta_{\mathrm{k}}$-demicontractive mapping.

It follows from Lemma 2.3 for each $i \in\{1,2, \ldots, m\}, j \in\{1,2, \ldots, \ell\}, k \in\{1,2, \ldots, s\}, \lambda_{i} \in\left(0,1-\sigma_{i}\right), \beta_{j} \in$ $\left(0,1-r_{j}\right)$, and $\eta_{k} \in\left(0,1-\delta_{k}\right)$ that

(i) $M_{i \lambda_{i}}$ is a demiclosed $\left(1-\sigma_{i}-\lambda_{i}\right)$-strongly quasi-nonexpansive mapping;

(ii) $Q_{j} \beta_{j}$ is a demiclosed $\left(1-r_{j}-\beta_{j}\right)$-strongly quasi-nonexpansive mapping;

(iii) $G_{k \eta_{k}}$ is a demiclosed $\left(1-\delta_{k}-\eta_{k}\right)$-strongly quasi-nonexpansive mapping.

It is easy to see that

(i) $\operatorname{Fix}\left(M_{i \lambda_{i}}\right)=\operatorname{Fix}\left(M_{i}\right)$;

(ii) $\operatorname{Fix}\left(Q_{j} \beta_{j}\right)=\operatorname{Fix}\left(Q_{j}\right)$;

(iii) $\operatorname{Fix}\left(G_{k \eta_{k}}\right)=\operatorname{Fix}\left(G_{k}\right)$.

Let $\Omega=\left\{(x, y, z) \in \bigotimes_{1 \leqslant i \leqslant 3} H_{i}: x \in \bigcap_{i=1}^{m} \operatorname{Fix}\left(M_{i \lambda_{i}}\right), y \in \bigcap_{j=1}^{\ell} \operatorname{Fix}\left(Q_{j \beta_{j}}\right), z \in \bigcap_{k=1}^{s} \operatorname{Fix}\left(G_{k \eta_{k}}\right)\right), A_{1}(x)=$ $\left.A_{2}(y)=A_{3}(z)\right\}$.

It is easy to see that $\Omega=\Lambda \neq \emptyset$. Then Theorem 3.5 follows from Theorem 3.3.

Remark 3.6.

(i) Theorem 3.5 improves and generalizes [24, Theorem 3.2] and [22, Theorem 3.3]. In [22, Theorem 3.3], $V=\left(f_{1}, f_{2}\right)$ is a contraction mapping and $F=\left(I_{1}, I_{2}\right)$.

(ii) Theorem 3.5 extends [14, Theorem 4.1] from variational inequality over split equality fixed points of $\mathrm{m}$ demicontractive mappings to variational inequality over split equality of three families of demicontractive mappings.

Corollary 3.7. For each $i \in\{1,2, \ldots, m\}, j \in\{1,2, \ldots, \ell\}, k \in\{1,2, \ldots, s\}$, let

(i) $\mathrm{M}_{\mathrm{i}}: \mathrm{H}_{1} \rightarrow \mathrm{H}_{1}$ be a demiclosed quasi-nonexpansive mapping;

(ii) $\mathrm{Q}_{\mathrm{j}}: \mathrm{H}_{2} \rightarrow \mathrm{H}_{2}$ be a demiclosed quasi-nonexpansive m mapping;

(iii) $\mathrm{G}_{\mathrm{k}}: \mathrm{H}_{3} \rightarrow \mathrm{H}_{3}$ be a demiclosed quasi-nonexpansive mapping.

Let

(i) $M_{i \lambda_{i}}=\left(1-\lambda_{i}\right) I_{1}+\lambda_{i} M_{i}$ for $\lambda_{i} \in(0,1)$;

(ii) $Q_{j} \beta_{j}=\left(1-\beta_{j}\right) I_{2}+\beta_{j} Q_{j}$ for $\beta_{j} \in(0,1)$;

(iii) $\mathrm{G}_{\mathrm{k} \eta_{\mathrm{k}}}=\left(1-\eta_{\mathrm{k}}\right) \mathrm{I}_{3}+\eta_{\mathrm{k}} \mathrm{G}_{\mathrm{k}}$ for $\eta_{\mathrm{k}} \in(0,1)$.

Let $\left(\zeta_{1}, \zeta_{2}, \ldots, \zeta_{m}\right) \in \Delta_{m},\left(\theta_{1}, \theta_{2}, \ldots, \theta_{\ell}\right) \in \Delta_{\ell},\left(\omega_{1}, \omega_{2}, \ldots, \omega_{s}\right) \in \Delta_{s}$. Suppose that

$$
\Lambda=\left\{(x, y, z) \in \bigotimes_{1 \leqslant i \leqslant 3} H_{i}: x \in \bigcap_{i=1}^{m} \operatorname{Fix}\left(M_{i}\right), y \in \bigcap_{j=1}^{\ell} \operatorname{Fix}\left(Q_{j}\right), z \in \bigcap_{k=1}^{s} \operatorname{Fix}\left(G_{k}\right), A_{1}(x)=A_{2}(y)=A_{3}(z)\right\} \neq \emptyset .
$$

Let $x_{1} \in H_{1}, y_{1} \in H_{2}, z_{1} \in H_{3}$, and let the sequences $\left\{\left(x_{n}, y_{n}, z_{n}\right)\right\}_{n} \in \mathbb{N}$ be defined by

(i) $x_{n+1}=\alpha_{n} \gamma V_{1}\left(x_{n}\right)+\left(I_{1}-\mu \alpha_{n} F_{1}\right) \sum_{i=1}^{m} \zeta_{i} M_{i \lambda_{i}}\left(x_{n}-\frac{\xi}{3} A_{1}^{*}\left(2 A_{1}\left(x_{n}\right)-A_{2}\left(y_{n}\right)-A_{3}\left(z_{n}\right)\right)\right)$ for all $n \in \mathbb{N}$;

(ii) $y_{n+1}=\alpha_{n} \gamma V_{2}\left(y_{n}\right)+\left(I_{2}-\mu \alpha_{n} F_{2}\right) \sum_{j=1}^{\ell} \theta_{j} Q_{j} \beta_{j}\left(y_{n}-\frac{\xi}{3} A_{2}^{*}\left(2 A_{2}\left(y_{n}\right)-A_{1}\left(x_{n}\right)-A_{3}\left(z_{n}\right)\right)\right)$ for all $n \in \mathbb{N}$; 
(iii) $z_{n+1}=\alpha_{n} \gamma V_{3}\left(z_{n}\right)+\left(I_{3}-\mu \alpha_{n} F_{3}\right) \sum_{k=1}^{s} \omega_{k} G_{k \eta_{k}}\left(z_{n}-\frac{\xi}{3} A_{3}^{*}\left(2 A_{3}\left(z_{n}\right)-A_{1}\left(x_{n}\right)-A_{2}\left(y_{n}\right)\right)\right)$ for all $n \in$ $\mathbb{N}$.

Then $\lim _{n \rightarrow \infty}\left(x_{n}, y_{n}, z_{n}\right) \in V I(\mu F-\gamma V, \Lambda)$.

Proof. Since a quasi-nonexpansive mapping is a 0-demicontractive mapping, Corollary 3.7 follows from Theorem 3.5.

\section{Remark 3.8.}

(i) Corollary 3.7 improves and generalizes [13, Theorem 3.1]. [13, Theorem 3.1] established a strong convergence theorem for $\mathrm{VI}(\mathrm{L}-\gamma f, \Lambda)$, where $\mathrm{L}$ is a strongly positive bounded self-adjoint linear operator, $f$ is a contraction mapping, and $\Lambda$ is a multiple sets split fixed point of quasi-nonexpansive mappings. Since a strongly positive bounded self-adjoint operator is a Lipschitz continuous and strongly monotone operator.

(ii) Corollary 3.7 generalizes [5, Corollary 5.1] which established a weak convergence of multiple sets split fixed point theorem of quasi-nonexpansive mappings.

(iii) Corollary 3.7 also extends [27, Theorems 3.2 and 3.4]. In [27, Theorems 3.2 and 3.4], $V=\left(f_{1}, f_{2}\right)$ is a contraction mapping and $\mathrm{F}=\left(\mathrm{I}_{1}, \mathrm{I}_{2}\right)$.

Theorem 3.9. For each $i \in\{1,2, \ldots, m\}, j \in\{1,2, \ldots, \ell\}, k \in\{1,2, \ldots, s\}$, let

(i) $\mathrm{M}_{\mathrm{i}}: \mathrm{H}_{1} \rightarrow \mathrm{H}_{1}$ be a $\sigma_{i}$-strictly pseudo-nonspreading mapping;

(ii) $\mathrm{Q}_{\mathrm{j}}: \mathrm{H}_{2} \rightarrow \mathrm{H}_{2}$ be a $\mathrm{r}_{\mathrm{j}}$-strictly pseudo-nonspreading mapping;

(iii) $\mathrm{G}_{\mathrm{k}}: \mathrm{H}_{3} \rightarrow \mathrm{H}_{3}$ be a demiclosed $\delta_{\mathrm{k}}$-strictly pseudo-nonspreading mapping.

Let

(i) $M_{i \lambda_{i}}=\left(1-\lambda_{i}\right) I_{1}+\lambda_{i} M_{i}$ for $\lambda_{i} \in\left(\sigma_{i}, 1\right)$;

(ii) $Q_{j} \beta_{j}=\left(1-\beta_{j}\right) I_{2}+\beta_{j} Q_{j}$ for $\beta_{j} \in\left(r_{j}, 1\right)$;

(iii) $\mathrm{G}_{\mathrm{k} \eta_{\mathrm{k}}}=\left(1-\eta_{\mathrm{k}}\right) \mathrm{I}_{3}+\eta_{\mathrm{k}} \mathrm{G}_{\mathrm{k}}$ for $\eta_{\mathrm{k}} \in\left(\delta_{\mathrm{k}}, 1\right)$.

Let $\left(\zeta_{1}, \zeta_{2}, \ldots, \zeta_{m}\right) \in \Delta_{m},\left(\theta_{1}, \theta_{2}, \ldots, \theta_{\ell}\right) \in \Delta_{\ell},\left(\omega_{1}, \omega_{2}, \ldots, \omega_{s}\right) \in \Delta_{s}$. Suppose that

$\Lambda=\left\{(x, y, z) \in \bigotimes_{1 \leqslant i \leqslant 3} H_{i}: x \in \bigcap_{i=1}^{m} \operatorname{Fix}\left(M_{i}\right), y \in \bigcap_{j=1}^{\ell} \operatorname{Fix}\left(Q_{j}\right), z \in \bigcap_{k=1}^{s} \operatorname{Fix}\left(G_{k}\right), A_{1}(x)=A_{2}(y)=A_{3}(z)\right\} \neq \emptyset$.

Let $x_{1} \in H_{1}, y_{1} \in H_{2}, z_{1} \in H_{3}$, and let the sequences $\left\{\left(x_{n}, y_{n}, z_{n}\right)\right\}_{n} \in \mathbb{N}$ be defined by

(i) $x_{n+1}=\alpha_{n} \gamma V_{1}\left(x_{n}\right)+\left(I_{1}-\mu \alpha_{n} F_{1}\right) \sum_{i=1}^{m} \zeta_{i} M_{i \lambda_{i}}\left(x_{n}-\frac{\xi}{3} A_{1}^{*}\left(2 A_{1}\left(x_{n}\right)-A_{2}\left(y_{n}\right)-A_{3}\left(z_{n}\right)\right)\right)$ for all $n \in \mathbb{N}$;

(ii) $y_{n+1}=\alpha_{n} \gamma V_{2}\left(y_{n}\right)+\left(I_{2}-\mu \alpha_{n} F_{2}\right) \sum_{j=1}^{\ell} \theta_{j} Q_{j} \beta_{j}\left(y_{n}-\frac{\xi}{3} A_{2}^{*}\left(2 A_{2}\left(y_{n}\right)-A_{1}\left(x_{n}\right)-A_{3}\left(z_{n}\right)\right)\right)$ for all $n \in \mathbb{N}$;

(iii) $z_{n+1}=\alpha_{n} \gamma V_{3}\left(z_{n}\right)+\left(I_{3}-\mu \alpha_{n} F_{3}\right) \sum_{k=1}^{s} \omega_{k} G_{k \eta_{k}}\left(z_{n}-\frac{\xi}{3} A_{3}^{*}\left(2 A_{3}\left(z_{n}\right)-A_{1}\left(x_{n}\right)-A_{2}\left(y_{n}\right)\right)\right.$ for all $n \in$ $\mathbb{N}$.

Then $\lim _{n \rightarrow \infty}\left(x_{n}, y_{n}, z_{n}\right) \in V I(\mu F-\gamma V, \Lambda)$.

Proof. By assumptions and Lemma 2.4, for each $i \in\{1,2, \ldots, m\}, j \in\{1,2, \ldots, \ell\}, k \in\{1,2, \ldots, s\}$, and for $\lambda_{i} \in\left(\sigma_{i}, 1\right), \beta_{j} \in\left(r_{j}, 1\right)$ and $\eta_{k} \in\left(\delta_{k}, 1\right)$ we have that

(i) $\operatorname{Fix}\left(M_{i \lambda_{i}}\right)=\operatorname{Fix}\left(M_{i}\right), \operatorname{Fix}\left(Q_{j \beta_{j}}\right)=\operatorname{Fix}\left(Q_{j}\right), \operatorname{Fix}\left(G_{k \eta_{k}}\right)=\operatorname{Fix}\left(G_{k}\right)$;

(ii) $M_{i \lambda_{i}}, Q_{j} \beta_{j}$, and $G_{k \eta_{k}}$ are demiclosed;

(iii) $\left\|M_{i \lambda_{i}} x-M_{i \lambda_{i}} y\right\|^{2} \leqslant\|x-y\|^{2}+\frac{2}{1-\lambda_{i}}\left\langle x-M_{i \lambda_{i}} x, y-M_{i \lambda_{i}} y\right\rangle-\left(\lambda_{i}-\sigma_{i}\right)\left\|x-M_{i \lambda_{i}} x-\left(y-M_{i \lambda_{i}} y\right)\right\|^{2}$;

(iv) $\left\|Q_{j \beta_{j}} x-Q_{j \beta_{j}} y\right\|^{2} \leqslant\|x-y\|^{2}+\frac{2}{1-\beta_{j}}\left\langle x-Q_{j \beta_{j}} x, y-Q_{j \beta_{j}} y\right\rangle-\left(\beta_{j}-r_{j}\right)\left\|x-Q_{j \beta_{j}} x-\left(y-Q_{j \beta_{j}} y\right)\right\|^{2}$;

(v) $\left\|G_{k \beta_{j}} x-Q_{j \beta_{j}} y\right\|^{2} \leqslant\|x-y\|^{2}+\frac{2}{1-\eta_{k}}\left\langle x-G_{k \eta_{k}} x, y-G_{k \eta_{k}} y\right\rangle-\left(\eta_{k}-\delta_{k}\right)\left\|x-G_{k \eta_{j}} x-\left(y-G_{j \eta_{k}} y\right)\right\|^{2}$. 
It is easy to see that for each $i \in\{1,2, \ldots, m\}, j \in\{1,2, \ldots, \ell\}, k \in\{1,2, \ldots, s\}$, and for $\lambda_{i} \in\left(\sigma_{i}, 1\right), \beta_{j} \in$ $\left(r_{j}, 1\right)$ and $\eta_{k} \in\left(\delta_{k}, 1\right)$ that

(i) $M_{i \lambda_{i}}$ is a demiclosed $\left(\lambda_{i}-\sigma_{i}\right)$-strongly quasi-nonexpansive mapping;

(ii) $Q_{j} \beta_{j}$ is a demiclosed $\left(\beta_{j}-r_{j}\right)$-strongly quasi-nonexpansive mapping;

(iii) $G_{k \eta_{k}}$ is a demiclosed $\left(\eta_{k}-\delta_{k}\right)$-strongly quasi-nonexpansive mapping.

Let

$$
\Omega=\left\{(x, y, z) \in \bigotimes_{1 \leqslant i \leqslant 3} H_{i}: x \in \bigcap_{i=1}^{m} \operatorname{Fix}\left(M_{i \lambda_{i}}\right), y \in \bigcap_{j=1}^{\ell} \operatorname{Fix}\left(Q_{j \beta_{j}}\right), z \in \bigcap_{k=1}^{s} \operatorname{Fix}\left(G_{k \delta_{k}}\right), A_{1}(x)=A_{2}(y)=A_{3}(z)\right\}
$$

It is easy to see that $\Omega=\Lambda \neq \emptyset$. Then Theorem 3.9 follows from Theorem 3.3.

Remark 3.10.

(i) Theorem 3.9 improves and generalizes [10, Theorem 3.1]. [10, Theorem 3.1] established a weak convergence theorem for split equality multiple sets fixed point of strictly pseudo-nonspreading mappings. The simultaneous iteration in Theorem 3.9 is different from the simultaneous iterations in [10, Theorem 3.1].

(ii) In [14, Theorem 3.7], the authors studied variational inequality problem over split equality fixed point for $\mathrm{m}$ strictly pseudo-nonspreading mappings, but Theorem 3.9 studies variational inequality problem over split equality fixed point for three finite families of strictly pseudo-nonspreading mappings.

Theorem 3.11. For each $i \in\{1,2, \ldots, m\}, j \in\{1,2, \ldots, \ell\}, k \in\{1,2, \ldots, s\}$, let

(i) $\mathrm{M}_{\mathrm{i}}: \mathrm{H}_{1} \rightarrow \mathrm{H}_{1}$ be a $\sigma_{i}$-strictly pseudo-nonspreading mapping;

(ii) $\mathrm{Q}_{\mathrm{j}}: \mathrm{H}_{2} \rightarrow \mathrm{H}_{2}$ be a $\mathrm{r}_{\mathrm{j}}$-strictly pseudo-contractive mapping;

(iii) $\mathrm{G}_{\mathrm{k}}: \mathrm{H}_{3} \rightarrow \mathrm{H}_{3}$ be a demiclosed $\delta_{\mathrm{k}}$-demicontractive mapping.

Let

(i) $M_{i \lambda_{i}}=\left(1-\lambda_{i}\right) I_{1}+\lambda_{i} M_{i}$ for $\lambda_{i} \in\left(\sigma_{i}, 1\right)$;

(ii) $Q_{j} \beta_{j}=\left(1-\beta_{j}\right) I_{2}+\beta_{j} Q_{j}$ for $\beta_{j} \in\left(0,1-r_{j}\right)$;

(iii) $\mathrm{G}_{\mathrm{k} \eta_{\mathrm{k}}}=\left(1-\eta_{\mathrm{k}}\right) \mathrm{I}_{3}+\eta_{\mathrm{k}} \mathrm{G}_{\mathrm{k}}$ for $\eta_{\mathrm{k}} \in\left(0,1-\delta_{\mathrm{k}}\right)$.

Let $\left(\zeta_{1}, \zeta_{2}, \ldots, \zeta_{\mathrm{m}}\right) \in \Delta_{\mathrm{m}},\left(\theta_{1}, \theta_{2}, \ldots, \theta_{\ell}\right) \in \Delta_{\ell},\left(\omega_{1}, \omega_{2}, \ldots, \omega_{s}\right) \in \Delta_{s}$. Suppose that

$\Lambda=\left\{(x, y, z) \in \bigotimes_{1 \leqslant i \leqslant 3} H_{i}: x \in \bigcap_{i=1}^{m} \operatorname{Fix}\left(M_{i}\right), y \in \bigcap_{j=1}^{\ell} \operatorname{Fix}\left(Q_{j}\right), z \in \bigcap_{k=1}^{s} \operatorname{Fix}\left(G_{k}\right), A_{1}(x)=A_{2}(y)=A_{3}(z)\right\} \neq \emptyset$.

Let $x_{1} \in \mathrm{H}_{1}, \mathrm{y}_{1} \in \mathrm{H}_{2}, z_{1} \in \mathrm{H}_{3}$, and let the sequences $\left\{\left(x_{n}, y_{n}, z_{n}\right)\right\}_{n \in \mathbb{N}}$ be defined by

(i) $x_{n+1}=\alpha_{n} \gamma V_{1}\left(x_{n}\right)+\left(I_{1}-\mu \alpha_{n} F_{1}\right) \sum_{i=1}^{m} \zeta_{i} M_{i \lambda_{i}}\left(x_{n}-\frac{\xi}{3} A_{1}^{*}\left(2 A_{1}\left(x_{n}\right)-A_{2}\left(y_{n}\right)-A_{3}\left(z_{n}\right)\right)\right)$ for all $n \in \mathbb{N}$;

(ii) $y_{n+1}=\alpha_{n} \gamma V_{2}\left(y_{n}\right)+\left(I_{2}-\mu \alpha_{n} F_{2}\right) \sum_{j=1}^{\ell} \theta_{j} Q_{j} \beta_{j}\left(y_{n}-\frac{\xi}{3} A_{2}^{*}\left(2 A_{2}\left(y_{n}\right)-A_{1}\left(x_{n}\right)-A_{3}\left(z_{n}\right)\right)\right)$ for all $n \in \mathbb{N}$;

(iii) $z_{n+1}=\alpha_{n} \gamma V_{3}\left(z_{n}\right)+\left(I_{3}-\mu \alpha_{n} F_{3}\right) \sum_{k=1}^{s} \omega_{k} G_{k \eta_{k}}\left(z_{n}-\frac{\xi}{3} A_{3}^{*}\left(2 A_{3}\left(z_{n}\right)-A_{1}\left(x_{n}\right)-A_{2}\left(y_{n}\right)\right)\right.$ for all $n \in$ $\mathbb{N}$.

Then $\lim _{n \rightarrow \infty}\left(x_{n}, y_{n}, z_{n}\right) \in V I(\mu F-\gamma V, \Lambda)$.

Proof. We see in the proof of Theorem 3.9 that $M_{i \lambda_{i}}$ is a demiclosed $\left(\lambda_{i}-\sigma_{i}\right)$-strongly quasi-nonexpansive mapping and $\operatorname{Fix}\left(M_{i \lambda_{i}}\right)=\operatorname{Fix}\left(M_{i}\right)$ for each $i \in\{1,2, \ldots, m\}$.

Since for each $j \in\{1,2, \ldots, \ell\}, Q_{j}: H_{2} \rightarrow H_{2}$ is a $r_{j}$-strictly pseudo-contractive mapping. It is easy to see that $Q_{j}$ is a $r_{j}$-demicontractive mapping for each $j \in\{1,2, \ldots, \ell\}$. For each $j \in\{1,2, \ldots, \ell\}$, by Lemma 2.13, $\mathrm{Q}_{\mathrm{j}}$ is demiclosed.

It follows from Lemma 2.3 for each $j \in\{1,2, \ldots, \ell\}, k \in\{1,2, \ldots, s\}, \beta_{j} \in\left(0,1-r_{j}\right)$ and $\eta_{k} \in\left(0,1-\delta_{k}\right)$ that 
(i) $Q_{j \beta_{j}}$ is a demiclosed $\left(1-r_{j}-\beta_{j}\right)$-strongly quasi-nonexpansive mapping;

(ii) $G_{k \eta_{k}}$ is a demiclosed $\left(1-\delta_{k}-\eta_{k}\right)$-strongly quasi-nonexpansive mapping.

Let

$$
\Omega=\left\{(x, y, z) \in \bigotimes_{1 \leqslant i \leqslant 3} H_{i}: x \in \bigcap_{i=1}^{m} \operatorname{Fix}\left(M_{i \lambda_{i}}\right), y \in \bigcap_{j=1}^{\ell} \operatorname{Fix}\left(Q_{j \beta_{j}}\right), z \in \bigcap_{k=1}^{s} \operatorname{Fix}\left(G_{k \delta_{k}}\right), A_{1}(x)=A_{2}(y)=A_{3}(z)\right\}
$$

It is easy to see that $\Omega=\Lambda \neq \emptyset$. Then Theorem 3.11 follows from Theorem 3.3.

Corollary 3.12. Let $\mathrm{V}_{\mathrm{i}}: \mathrm{H}_{1} \rightarrow \mathrm{H}_{1}$ be $\mathrm{L}_{\mathrm{i}}$-Lipschitz continuous, $\mathrm{F}_{\mathrm{i}}: \mathrm{H}_{1} \rightarrow \mathrm{H}_{1}$ be $\mathrm{K}_{\mathrm{i}}$-Lipschitz continuous and $\eta_{i}$-strongly monotone with $\kappa_{i}>0$, and $\eta_{i}>0$. For each $i \in\{1,2, \ldots, m\}, j \in\{1,2, \ldots, \ell\}, k \in\{1,2, \ldots, s\}$, let

(i) $\mathrm{M}_{\mathrm{i}}: \mathrm{H}_{1} \rightarrow \mathrm{H}_{1}$ be a $\sigma_{i}$-strictly pseudo-nonspreading mapping;

(ii) $\mathrm{Q}_{\mathrm{j}}: \mathrm{H}_{1} \rightarrow \mathrm{H}_{1}$ be a $\mathrm{r}_{\mathrm{j}}$-strictly pseudo-contractive mapping;

(iii) $\mathrm{G}_{\mathrm{k}}: \mathrm{H}_{1} \rightarrow \mathrm{H}_{1}$ be a demiclosed $\delta_{\mathrm{k}}$-demicontractive mapping.

Let

(i) $M_{i \lambda_{i}}=\left(1-\lambda_{i}\right) I_{1}+\lambda_{i} M_{i}$ for $\lambda_{i} \in\left(\sigma_{i}, 1\right)$;

(ii) $Q_{j} \beta_{j}=\left(1-\beta_{j}\right) I_{1}+\beta_{j} Q_{j}$ for $\beta_{j} \in\left(0,1-r_{j}\right)$;

(iii) $\mathrm{G}_{\mathrm{k} \eta_{\mathrm{k}}}=\left(1-\eta_{\mathrm{k}}\right) \mathrm{I}_{1}+\eta_{\mathrm{k}} \mathrm{G}_{\mathrm{k}}$ for $\eta_{\mathrm{k}} \in\left(0,1-\delta_{\mathrm{k}}\right)$.

Let $\left(\zeta_{1}, \zeta_{2}, \ldots, \zeta_{\mathrm{m}}\right) \in \Delta_{\mathrm{m}},\left(\theta_{1}, \theta_{2}, \ldots, \theta_{\ell}\right) \in \Delta_{\ell},\left(\omega_{1}, \omega_{2}, \ldots, \omega_{s}\right) \in \Delta_{\mathrm{s}}$. Suppose that

$$
\Lambda=\left\{(x, x, x): x \in H_{1}, x \in \bigcap_{i=1}^{m} \operatorname{Fix}\left(M_{i}\right) \bigcap \bigcap_{j=1}^{\ell} \operatorname{Fix}\left(Q_{j}\right) \bigcap \bigcap_{k=1}^{s} \operatorname{Fix}\left(G_{k}\right)\right\} \neq \emptyset .
$$

Let $x_{1} \in H_{1}, y_{1} \in H_{1}, z_{1} \in H_{1}$, and let the sequences $\left\{\left(x_{n}, y_{n}, z_{n}\right)\right\}_{n} \in \mathbb{N}$ be defined by

(i) $x_{n+1}=\alpha_{n} \gamma V_{1}\left(x_{n}\right)+\left(I_{1}-\mu \alpha_{n} F_{1}\right) \sum_{i=1}^{m} \zeta_{i} M_{i} \lambda_{i}\left(x_{n}-\frac{\xi}{3}\left(2 x_{n}-y_{n}-z_{n}\right)\right)$ for all $n \in \mathbb{N}$;

(ii) $y_{n+1}=\alpha_{n} \gamma V_{2}\left(y_{n}\right)+\left(I_{1}-\mu \alpha_{n} F_{2}\right) \sum_{j=1}^{\ell} \theta_{j} Q_{j} \beta_{j}\left(y_{n}-\frac{\xi}{3}\left(2 y_{n}-x_{n}-z_{n}\right)\right)$ for all $n \in \mathbb{N}$;

(iii) $z_{n+1}=\alpha_{n} \gamma V_{3}\left(z_{n}\right)+\left(I_{1}-\mu \alpha_{n} F_{3}\right) \sum_{k=1}^{s} \omega_{k} G_{k \eta_{k}}\left(z_{n}-\frac{\xi}{3}\left(2 z_{n}-x_{n}-y_{n}\right)\right)$ for all $n \in \mathbb{N}$.

Then $\lim _{n \rightarrow \infty}\left(x_{n}, y_{n}, z_{n}\right) \in \operatorname{VI}(\mu F-\gamma V, \Lambda)$.

Proof. Let $\mathrm{H}_{1}=\mathrm{H}_{2}=\mathrm{H}_{3}=\mathrm{H}_{4}, \mathrm{~A}_{1}=\mathrm{I}_{1}=A_{2}=A_{3}$ in Theorem 3.11, then Corollary 3.12 follows from Theorem 3.11.

Theorem 3.13. Let $V_{i}: H_{1} \rightarrow H_{1}$ be $L_{i}$-Lipschitz continuous, $F_{i}: H_{1} \rightarrow H_{1}$ be $\kappa_{i}$-Lipschitz continuous and $\eta_{i}$-strongly monotone with $\kappa_{i}>0$, and $\eta_{i}>0$. For each $i \in\{1,2, \ldots, m\}, j \in\{1,2, \ldots, \ell\}, k \in\{1,2, \ldots, s\}$, let

(i) $\mathrm{M}_{\mathrm{i}}: \mathrm{H}_{1} \rightarrow \mathrm{H}_{1}$ be a $\sigma_{i}$-strictly pseudo-nonspreading mapping;

(ii) $\mathrm{Q}_{\mathrm{j}}: \mathrm{H}_{2} \rightarrow \mathrm{H}_{2}$ be a $\mathrm{r}_{j}$-strictly pseudo-contractive mapping;

(iii) $\mathrm{G}_{\mathrm{k}}: \mathrm{H}_{3} \rightarrow \mathrm{H}_{3}$ be a demiclosed $\delta_{\mathrm{k}}$-demicontractive mapping.

Let

(i) $M_{i \lambda_{i}}=\left(1-\lambda_{i}\right) I_{1}+\lambda_{i} M_{i}$ for $\lambda_{i} \in\left(\sigma_{i}, 1\right)$;

(ii) $Q_{j} \beta_{j}=\left(1-\beta_{j}\right) I_{2}+\beta_{j} Q_{j}$ for $\beta_{j} \in\left(0,1-r_{j}\right)$;

(iii) $G_{k \eta_{k}}=\left(1-\eta_{k}\right) I_{3}+\eta_{k} G_{k}$ for $\eta_{k} \in\left(0,1-\delta_{k}\right)$.

Let $\left(\zeta_{1}, \zeta_{2}, \ldots, \zeta_{m}\right) \in \Delta_{m},\left(\theta_{1}, \theta_{2}, \ldots, \theta_{\ell}\right) \in \Delta_{\ell},\left(\omega_{1}, \omega_{2}, \ldots, \omega_{s}\right) \in \Delta_{s}$. Suppose that

$$
\Lambda=\left\{(x, x, x): x \in H_{1}, x \in \bigcap_{i=1}^{m} \operatorname{Fix}\left(M_{i}\right), B_{1}(x) \in \bigcap_{j=1}^{\ell} \operatorname{Fix}\left(Q_{j}\right), B_{2}(x) \in \bigcap_{k=1}^{s} \operatorname{Fix}\left(G_{k}\right)\right\} \neq \emptyset .
$$

Let $x_{1} \in H_{1}, y_{1} \in H_{1}, z_{1} \in H_{1}$, and let the sequences $\left\{\left(x_{n}, y_{n}, z_{n}\right)\right\}_{n \in \mathbb{N}}$ be defined by 
(i) $x_{n+1}=\alpha_{n} \gamma V_{1}\left(x_{n}\right)+\left(I_{1}-\mu \alpha_{n} F_{1}\right) \sum_{i=1}^{m} \zeta_{i} M_{i \lambda_{i}}\left(x_{n}-\frac{\xi}{3}\left(2 x_{n}-y_{n}-z_{n}\right)\right)$ for all $n \in \mathbb{N}$;

(ii) $y_{n+1}=\alpha_{n} \gamma V_{2}\left(y_{n}\right)+\left(I_{1}-\mu \alpha_{n} F_{2}\right) \sum_{j=1}^{\ell} \theta_{j}\left(I_{1}-\frac{1}{\left\|B_{1}\right\|^{2}} B_{1}^{*}\left(I_{2}-Q_{j} \beta_{j}\right) B_{1}\right)\left(y_{n}-\frac{\xi}{3}\left(2 y_{n}-x_{n}-z_{n}\right)\right)$ for all $n \in \mathbb{N}$;

(iii) $z_{n+1}=\alpha_{n} \gamma V_{3}\left(z_{n}\right)+\left(I_{1}-\mu \alpha_{n} F_{3}\right) \sum_{k=1}^{s} \omega_{k}\left(I_{1}-\frac{1}{\left\|B_{2}\right\|^{2}} B_{2}^{*}\left(I_{3}-G_{k \eta_{k}}\right) B_{2}\right)\left(z_{n}-\frac{\xi}{3}\left(2 z_{n}-x_{n}-y_{n}\right)\right)$ for all $n \in \mathbb{N}$.

Then $\lim _{n \rightarrow \infty}\left(x_{n}, y_{n}, z_{n}\right) \in V I(\mu F-\gamma V, \Lambda)$.

Proof. Theorem 3.11 shows that for each $j \in\{1,2, \ldots, \ell\}, k \in\{1,2, \ldots, s\}, \beta_{j} \in\left(0,1-r_{j}\right)$, and $\eta_{k} \in\left(0,1-\delta_{k}\right)$,

(i) $Q_{j} \beta_{j}$ is a demiclosed $\left(1-r_{j}-\beta_{j}\right)$-strongly quasi-nonexpansive mapping;

(ii) $G_{k \eta_{k}}$ is a demiclosed $\left(1-\delta_{k}-\eta_{k}\right)$-strongly quasi-nonexpansive mapping.

Let

(i) $V_{j \beta_{j}}=\left(I_{1}-\frac{1}{\left\|B_{1}\right\|^{2}} B_{1}^{*}\left(I_{2}-Q_{j \beta_{j}}\right) B_{1}\right)$;

(ii) $W_{k \eta_{k}}=\left(I_{1}-\frac{1}{\left\|B_{2}\right\|^{2}} B_{2}^{*}\left(I_{3}-G_{k \eta_{k}}\right) B_{2}\right)$.

By Proposition 2.8, for $\beta_{j} \in\left(0,1-r_{j}\right)$, and for $\eta_{k} \in\left(0,1-\delta_{k}\right)$,

(i) $\operatorname{Fix}\left(V_{j \beta_{j}}\right)=B_{1}^{-1} \operatorname{Fix}\left(Q_{j}\right)$ and $\operatorname{Fix}\left(W_{k \eta_{k}}\right)=B_{2}^{-1} \operatorname{Fix}\left(G_{k}\right)$.

(ii) $V_{j \beta_{j}}: H_{1} \rightarrow H_{1}$ is a demiclosed $\left(1-r_{j}-\beta_{j}\right)$-strongly quasi-nonexpansive mapping, and $W_{k \eta_{k}}$ : $\mathrm{H}_{1} \rightarrow \mathrm{H}_{1}$ is a demiclosed $\left(1-\delta_{\mathrm{k}}-\eta_{\mathrm{k}}\right)$-strongly quasi-nonexpansive mapping.

Theorem 3.11 shows that $M_{i \lambda_{i}}$ is a demiclosed $\left(\lambda_{i}-\sigma_{i}\right)$-strongly quasi-nonexpansive mapping for $\lambda_{i} \in\left(\sigma_{i}, 1\right)$, and $\operatorname{Fix}\left(M_{i \lambda_{i}}\right)=\operatorname{Fix}\left(M_{i}\right)$.

Let

$$
\Omega=\left\{(x, x, x): x \in H_{1}, x \in \bigcap_{i=1}^{m} \operatorname{Fix}\left(M_{i \lambda_{i}}\right), x \in \bigcap_{j=1}^{\ell} \operatorname{Fix}\left(V_{j} \beta_{j}\right), x \in \bigcap_{k=1}^{s} \operatorname{Fix}\left(W_{k \eta_{k}}\right)\right\} .
$$

It is easy to see that $\Omega=\Lambda \neq \emptyset$. Then Theorem 3.13 follows from Corollary 3.12.

Theorem 3.14. For each $i \in\{1,2, \ldots, m\}, j \in\{1,2, \ldots, \ell\}, k \in\{1,2, \ldots, s\}$, let

(i) $\mathrm{P}_{\mathrm{i}}: \mathrm{H}_{1} \rightarrow \mathrm{H}_{1}$ be a $\sigma_{i}$-Lipschitz continuous demiclosed quasi-pseudocontractive mapping;

(ii) $\mathrm{R}_{\mathrm{j}}: \mathrm{H}_{2} \rightarrow \mathrm{H}_{2}$ be a $\rho_{\mathrm{j}}$-Lipschitz continuous demiclosed quasi-pseudocontractive mapping;

(iii) $\mathrm{W}_{\mathrm{k}}: \mathrm{H}_{3} \rightarrow \mathrm{H}_{3}$ be a $\delta_{\mathrm{k}}$-Lipschitz continuous demiclosed quasi-pseudocontractive mapping.

For each $i \in\{1,2, \ldots, m\}, j \in\{1,2, \ldots, \ell\}$, and $k \in\{1,2, \ldots, s\}$, let

(i) $M_{i}=\left(1-\xi_{i}\right) I_{1}+\xi_{i} P_{i}\left(1-\gamma_{i}\right) I_{1}+\gamma_{1} P_{i}$;

(ii) $Q_{j}=\left(1-\sigma_{j}\right) I_{2}+\sigma_{j} R_{j}\left(1-v_{j}\right) I_{2}+v_{j} R_{j}$;

(iii) $\mathrm{G}_{\mathrm{k}}=\left(1-\rho_{\mathrm{k}}\right) \mathrm{I}_{3}+\rho_{\mathrm{k}} \mathrm{W}_{\mathrm{k}}\left(1-\delta_{\mathrm{k}}\right) \mathrm{I}_{3}+\delta_{\mathrm{k}} \mathrm{W}_{\mathrm{k}}$,

where $0<\xi_{i}<\gamma_{i}<\frac{1}{1+\sqrt{1+\sigma_{i}^{2}}}, i \in\{1,2, \ldots, m\}, 0<\omega_{j}<v_{j}<\frac{1}{1+\sqrt{1+\rho_{j}^{2}}}, j \in\{1,2, \ldots, \ell\}$, and $0<\rho_{k}<\xi_{k}<$ $\frac{1}{1+\sqrt{1+\delta_{\mathrm{k}}^{2}}}, \mathrm{k} \in\{1,2, \ldots, \mathrm{s}\}$, and let

(i) $M_{i \lambda_{i}}=\left(1-\lambda_{i}\right) I_{1}+\lambda_{i} M_{i}$ for $\lambda_{i} \in(0,1)$;

(ii) $Q_{j \beta_{j}}=\left(1-\beta_{j}\right) I_{2}+\beta_{j} Q_{j}$ for $\beta_{j} \in(0,1)$;

(iii) $\mathrm{G}_{\mathrm{k} \eta_{\mathrm{k}}}=\left(1-\eta_{\mathrm{k}}\right) \mathrm{I}_{3}+\eta_{\mathrm{k}} \mathrm{G}_{\mathrm{k}}$ for $\eta_{\mathrm{k}} \in(0,1)$.

Let $\left(\zeta_{1}, \zeta_{2}, \ldots, \zeta_{\mathrm{m}}\right) \in \Delta_{\mathrm{m}},\left(\theta_{1}, \theta_{2}, \ldots, \theta_{\ell}\right) \in \Delta_{\ell},\left(\omega_{1}, \omega_{2}, \ldots, \omega_{s}\right) \in \Delta_{s}$. Suppose that $\left.\Lambda=\left\{(x, y, z) \in \bigotimes_{1 \leqslant i \leqslant 3} H_{i}: x \in \bigcap_{i=1}^{m} \operatorname{Fix}\left(P_{i}\right), y \in \bigcap_{j=1}^{\ell} \operatorname{Fix}\left(R_{j}\right), z \in \bigcap_{k=1}^{s} \operatorname{Fix}\left(W_{k}\right)\right), A_{1}(x)=A_{2}(y)=A_{3}(z)\right\} \neq \emptyset$.

Let $x_{1} \in H_{1}, y_{1} \in H_{2}, z_{1} \in H_{3}$, and let the sequences $\left\{\left(x_{n}, y_{n}, z_{n}\right)\right\}_{n} \in \mathbb{N}$ be defined by 
(i) $x_{n+1}=\alpha_{n} \gamma V_{1}\left(x_{n}\right)+\left(I_{1}-\mu \alpha_{n} F_{1}\right) \sum_{i=1}^{m} \zeta_{i} M_{i \lambda_{i}}\left(x_{n}-\frac{\xi}{3} A_{1}^{*}\left(2 A_{1}\left(x_{n}\right)-A_{2}\left(y_{n}\right)-A_{3}\left(z_{n}\right)\right)\right)$ for all $n \in \mathbb{N}$;

(ii) $y_{n+1}=\alpha_{n} \gamma V_{2}\left(y_{n}\right)+\left(I_{2}-\mu \alpha_{n} F_{2}\right) \sum_{j=1}^{\ell} \theta_{j} Q_{j} \beta_{j}\left(y_{n}-\frac{\xi}{3} A_{2}^{*}\left(2 A_{2}\left(y_{n}\right)-A_{1}\left(x_{n}\right)-A_{3}\left(z_{n}\right)\right)\right)$ for all $n \in \mathbb{N}$;

(iii) $z_{n+1}=\alpha_{n} \gamma V_{3}\left(z_{n}\right)+\left(I_{3}-\mu \alpha_{n} F_{3}\right) \sum_{k=1}^{s} \omega_{k} G_{k \eta_{k}}\left(z_{n}-\frac{\xi}{3} A_{3}^{*}\left(2 A_{3}\left(z_{n}\right)-A_{1}\left(x_{n}\right)-A_{2}\left(y_{n}\right)\right)\right.$ for all $n \in$ $\mathbb{N}$.

Then $\lim _{n \rightarrow \infty}\left(x_{n}, y_{n}, z_{n}\right) \in V I(\mu F-\gamma V, \Lambda)$.

Proof. By Lemma 2.11, for each $i \in\{1,2, \ldots, m\}, j \in\{1,2, \ldots, \ell\}, k \in\{1,2, \ldots, s\}$,

(i) $\operatorname{Fix}\left(M_{i}\right)=\operatorname{Fix}\left(P_{i}\right), \operatorname{Fix}\left(R_{j}\right)=\operatorname{Fix}\left(Q_{j}\right), \operatorname{Fix}\left(W_{k}\right)=\operatorname{Fix}\left(G_{k}\right)$;

(ii) $M_{i}, Q_{j}$, and $G_{k}$ are demiclosed at 0 ;

(iii) $M_{i}, Q_{j}$, and $G_{k}$ are quasi-nonexpansive mappings.

Let

$$
\Omega=\left\{(x, y, z) \in \bigotimes_{1 \leqslant i \leqslant 3} H_{i}: x \in \bigcap_{i=1}^{m} \operatorname{Fix}\left(M_{i}\right), y \in \bigcap_{j=1}^{\ell} \operatorname{Fix}\left(Q_{j}\right), z \in \bigcap_{k=1}^{s} \operatorname{Fix}\left(G_{k}\right), A_{1}(x)=A_{2}(y)=A_{3}(z)\right\} \neq \emptyset .
$$

It is easy to see that $\Omega=\Lambda \neq \emptyset$ and Theorem 3.14 follows from Corollary 3.7.

Remark 3.15. Since firmly quasinonexpansive mapping, pseudo-contractive mappings, k-strict pseudocontractive mapping, k-strict pseudo-nonspreading mapping, demi-contractive mappings, and directed operators are special cases of quasi-pseudo-contractive mappings, we see that Theorem 3.14 extends many results on fixed point problems, multiple sets split fixed point problems and split equality fixed point problems existing in the literature.

Corollary 3.16. For each $i \in\{1,2, \ldots, m\}, j \in\{1,2, \ldots, \ell\}, k \in\{1,2, \ldots, s\}$, let

(i) $\mathrm{P}_{i}: \mathrm{H}_{1} \rightarrow \mathrm{H}_{1}$ be a $\sigma_{i}$-Lipschitz continuous demiclosed quasi-pseudocontractive mapping;

(ii) $\mathrm{R}_{\mathrm{j}}: \mathrm{H}_{2} \rightarrow \mathrm{H}_{2}$ be a $\rho_{\mathrm{j}}$-Lipschitz continuous demiclosed quasi-pseudocontractive mapping;

(iii) $\mathrm{W}_{\mathrm{k}}: \mathrm{H}_{3} \rightarrow \mathrm{H}_{3}$ be a $\delta_{\mathrm{k}}$-Lipschitz continuous demiclosed quasi-pseudocontractive mapping.

For each $i \in\{1,2, \ldots, m\}, j \in\{1,2, \ldots, \ell\}$, and $k \in\{1,2, \ldots, s\}$, let

(i) $M_{i}=\left(1-\xi_{i}\right) I_{1}+\xi_{i} P_{i}\left(1-\gamma_{i}\right) I_{1}+\gamma_{1} P_{i}$;

(ii) $Q_{j}=\left(1-\sigma_{j}\right) I_{2}+\sigma_{j} R_{j}\left(1-v_{j}\right) I_{2}+v_{j} R_{j}$;

(iii) $\mathrm{G}_{\mathrm{k}}=\left(1-\rho_{\mathrm{k}}\right) \mathrm{I}_{3}+\rho_{\mathrm{k}} \mathrm{W}_{\mathrm{k}}\left(1-\delta_{\mathrm{k}}\right) \mathrm{I}_{3}+\delta_{\mathrm{k}} \mathrm{W}_{\mathrm{k}}$.

where $0<\xi_{i}<\gamma_{i}<\frac{1}{1+\sqrt{1+\sigma_{i}^{2}}}, i \in\{1,2, \ldots, m\}, 0<\omega_{j}<v_{j}<\frac{1}{1+\sqrt{1+\rho_{j}^{2}}}, j \in\{1,2, \ldots, \ell\}$, and $0<\rho_{k}<\xi_{k}<$ $\frac{1}{1+\sqrt{1+\delta_{k}^{2}}}, k \in\{1,2, \ldots, s\}$, and let

(i) $M_{i \lambda_{i}}=\left(1-\lambda_{i}\right) I_{1}+\lambda_{i} M_{i}$ for $\lambda_{i} \in(0,1)$;

(ii) $Q_{j} \beta_{j}=\left(1-\beta_{j}\right) I_{2}+\beta_{j} Q_{j}$ for $\beta_{j} \in(0,1)$;

(iii) $\mathrm{G}_{\mathrm{k} \eta_{\mathrm{k}}}=\left(1-\eta_{\mathrm{k}}\right) \mathrm{I}_{3}+\eta_{\mathrm{k}} \mathrm{G}_{\mathrm{k}}$ for $\eta_{\mathrm{k}} \in(0,1)$.

Let $\left(\zeta_{1}, \zeta_{2}, \ldots, \zeta_{m}\right) \in \Delta_{m},\left(\theta_{1}, \theta_{2}, \ldots, \theta_{\ell}\right) \in \Delta_{\ell},\left(\omega_{1}, \omega_{2}, \ldots, \omega_{s}\right) \in \Delta_{s}$.

Suppose that

$$
\left.\Lambda=\left\{(x, y, z) \in \bigotimes_{1 \leqslant i \leqslant 3} H_{i}: x \in \bigcap_{i=1}^{m} \operatorname{Fix}\left(P_{i}\right), y \in \bigcap_{j=1}^{\ell} \operatorname{Fix}\left(R_{j}\right), z \in \bigcap_{k=1}^{s} \operatorname{Fix}\left(W_{k}\right)\right), A_{1}(x)=A_{2}(y)=A_{3}(z)\right\} \neq \emptyset .
$$

Let $x_{1} \in H_{1}, y_{1} \in H_{2}, z_{1} \in H_{3}$, and let the sequences $\left\{\left(x_{n}, y_{n}, z_{n}\right)\right\}_{n \in \mathbb{N}}$ be defined by

(i) $x_{n+1}=\alpha_{n} x_{1}+\left(1-\alpha_{n}\right) \sum_{i=1}^{m} \zeta_{i} M_{i \lambda_{i}}\left(x_{n}-\frac{\xi}{3} A_{1}^{*}\left(2 A_{1}\left(x_{n}\right)-A_{2}\left(y_{n}\right)-A_{3}\left(z_{n}\right)\right)\right)$ for all $n \in \mathbb{N}$; 
(ii) $y_{n+1}=\alpha_{n} y_{1}+\left(1-\alpha_{n}\right) \sum_{j=1}^{\ell} \theta_{j} Q_{j} \beta_{j}\left(y_{n}-\frac{\xi}{3} A_{2}^{*}\left(2 A_{2}\left(y_{n}\right)-A_{1}\left(x_{n}\right)-A_{3}\left(z_{n}\right)\right)\right)$ for all $n \in \mathbb{N}$;

(iii) $z_{n+1}=\alpha_{n} z_{1}+\left(1-\alpha_{n}\right) \sum_{k=1}^{s} \omega_{k} G_{k \eta_{k}}\left(z_{n}-\frac{\xi}{3} A_{3}^{*}\left(2 A_{3}\left(z_{n}\right)-A_{1}\left(x_{n}\right)-A_{2}\left(y_{n}\right)\right)\right)$ for all $n \in \mathbb{N}$.

Then $\lim _{n \rightarrow \infty}\left(x_{n}, y_{n}, z_{n}\right)=P_{\wedge}\left(x_{1}, y_{1}, z_{1}\right)$.

Proof. Let $\mathrm{V}(\mathrm{x}, \mathrm{y}, z)=\left(\mathrm{V}_{1}(\mathrm{x}), \mathrm{V}_{2}(\mathrm{y}), \mathrm{V}_{3}(z)\right)=\left(\mathrm{x}_{1}, \mathrm{y}_{1}, z_{1}\right)$ for any $(x, y, z) \in \bigotimes_{1 \leqslant i \leqslant 3} H_{i}$, and let $\mathrm{F}=\mathrm{I}_{1} \times \mathrm{I}_{2} \times$ $\mathrm{I}_{3}$, then $\mathrm{V}$ is $\frac{1}{6}$-Lipschitz continuous. We choose $\mu=1, \gamma=1$, and $\tau=\frac{1}{2}$. Then Corollary 3.16 follows from Theorem 3.14.

Remark 3.17. Chang et al. [9] introduced an iteration process to study the split equality fixed point of quasi-pseudocontractive mappings and established a weak convergence theorem, they also established a strong convergence theorem under the assumption that both the quasi-pseudocontractive mappings which are considered by them are semicompactness, but we don't have the assumption of semi-compact on any one of operators in Theorem 3.14 and Corollary 3.16. We give a different proof to establish strong convergence theorem for the split equality fixed point of quasi-pseudocontractive mappings.

Theorem 3.18. For each $i \in\{1,2, \ldots, m\}, j \in\{1,2, \ldots, \ell\}, k \in\{1,2, \ldots, s\}$, let

(i) $\mathrm{M}_{\mathrm{i}}: \mathrm{H}_{1} \rightarrow \mathrm{H}_{1}$ be a hemicontinuous, locally bounded pseudocontractive mapping;

(ii) $\mathrm{Q}_{\mathrm{j}}: \mathrm{H}_{2} \rightarrow \mathrm{H}_{2}$ be a hemicontinuous, locally bounded monotone mapping;

(iii) $\mathrm{G}_{\mathrm{k}}: \mathrm{H}_{3} \rightarrow \mathrm{H}_{3}$ be a demiclosed $\delta_{\mathrm{k}}$ - demicontractive mapping.

Let $r>0$, for $x \in H_{1}$, and $u \in H_{2}$, and set

(i) $S_{i}(x)=\left\{z \in H_{1}:\left\langle y-z, M_{i} z\right\rangle-\frac{1}{r}\langle y-z,(1+r) z-x\rangle \leqslant 0, \forall y \in H_{i}\right\}$;

(ii) $P_{j}(u)=\left\{z \in D_{j}:\left\langle y-z, Q_{j}(z)\right\rangle+\frac{1}{r}\langle y-z, z-u\rangle \geqslant 0, \forall y \in D_{j}\right\}$;

(iii) $G_{k \eta_{k}}=\left(1-\eta_{k}\right) I_{3}+\eta_{k} G_{k}$ for $\eta_{k} \in\left(0,1-\delta_{k}\right)$.

Let $\left(\zeta_{1}, \zeta_{2}, \ldots, \zeta_{m}\right) \in \Delta_{m},\left(\theta_{1}, \theta_{2}, \ldots, \theta_{\ell}\right) \in \Delta_{\ell},\left(\omega_{1}, \omega_{2}, \ldots, \omega_{s}\right) \in \Delta_{s}$. Suppose that $\Lambda=\left\{(x, y, z) \in \bigotimes_{1 \leqslant i \leqslant 3} H_{i}: x \in \bigcap_{i=1}^{m} \operatorname{Fix}\left(M_{i}\right), y \in \bigcap_{j=1}^{\ell} V I\left(Q_{j}, D_{j}\right), z \in \bigcap_{k=1}^{s} \operatorname{Fix}\left(G_{k}\right), A_{1}(x)=A_{2}(y)=A_{3}(z)\right\} \neq \emptyset$.

Let $x_{1} \in H_{1}, y_{1} \in H_{2}, z_{1} \in H_{3}$, and let the sequences $\left\{\left(x_{n}, y_{n}, z_{n}\right)\right\}_{\mathfrak{n} \in \mathbb{N}}$ be defined by

(i) $x_{n+1}=\alpha_{n} \gamma V_{1}\left(x_{n}\right)+\left(I_{1}-\mu \alpha_{n} F_{1}\right) \sum_{i=1}^{m} \zeta_{i} S_{i}\left(x_{n}-\frac{\xi}{3} A_{1}^{*}\left(2 A_{1}\left(x_{n}\right)-A_{2}\left(y_{n}\right)-A_{3}\left(z_{n}\right)\right)\right)$ for all $n \in \mathbb{N}$;

(ii) $y_{n+1}=\alpha_{n} \gamma V_{2}\left(y_{n}\right)+\left(I_{2}-\mu \alpha_{n} F_{2}\right) \sum_{j=1}^{\ell} \theta_{j} P_{j}\left(y_{n}-\frac{\xi}{3} A_{2}^{*}\left(2 A_{2}\left(y_{n}\right)-A_{1}\left(x_{n}\right)-A_{3}\left(z_{n}\right)\right)\right)$ for all $n \in \mathbb{N}$;

(iii) $z_{n+1}=\alpha_{n} \gamma V_{3}\left(z_{n}\right)+\left(I_{3}-\mu \alpha_{n} F_{3}\right) \sum_{k=1}^{s} \omega_{k} G_{k \eta_{k}}\left(z_{n}-\frac{\xi}{3} A_{3}^{*}\left(2 A_{3}\left(z_{n}\right)-A_{1}\left(x_{n}\right)-A_{2}\left(y_{n}\right)\right)\right)$ for all $n \in$ $\mathbb{N}$.

Then $\lim _{n \rightarrow \infty}\left(x_{n}, y_{n}, z_{n}\right) \in V I(\mu F-\gamma V, \Lambda)$.

Proof. We see in Theorem 3.5, for each $\eta \in\left(1-\lambda_{k}\right), G_{k \eta_{k}}$ is a demiclosed $\left(1-\delta_{k}-\eta_{k}\right)$-strongly quasinonexpansive mapping. By theorem 2.6, and Theorem 2.7, we show that for each $i \in\{1,2, \ldots, m\}$, and $j \in$ $\{1,2, \ldots, s\}$,

(i) $S_{i}$ and $P_{j}$ are single-valued;

(ii) $S_{i}$ and $P_{j}$ are firmly nonexpansive;

(iii) $\operatorname{Fix}\left(P_{j}\right)=V I\left(Q_{j}, D_{j}\right)$, and $\operatorname{Fix}\left(S_{i}\right)=\operatorname{Fix}\left(M_{i}\right)$.

Then for each $i \in\{1,2, \ldots, m\}$, and $j \in\{1,2, \ldots, s\}, S_{i}$ and $P_{j}$ are averaged. Therefore $S_{i}$ and $P_{j}$ are nonexpansive mappings. Then by Lemma 2.1, $S_{i}$ and $P_{j}$ are demiclosed. By Proposition 2.2, we show that

(i) $S_{i}$ is a $\rho_{i}$-strongly quasi-nonexpansive mapping for some $\rho_{i}>0$; 
(ii) $P_{j}$ is a demiclosed $\gamma_{j}$-strongly quasi-nonexpansive mapping for some $\gamma_{j}>0$.

Let

$$
\Omega=\left\{(x, y, z) \in \bigotimes_{1 \leqslant i \leqslant 3} H_{i}: x \in \bigcap_{i=1}^{m} \operatorname{Fix}\left(S_{i}\right), y \in \bigcap_{j=1}^{\ell} \operatorname{Fix}\left(P_{j}\right), z \in \bigcap_{k=1}^{s} \operatorname{Fix}\left(G_{k \eta_{k}}\right), A_{1}(x)=A_{2}(y)=A_{3}(z)\right\} .
$$

It is easy to see that $\Omega=\Lambda \neq \emptyset$. Then Theorem 3.18 follows from Theorem 3.3.

We apply Theorem 3.3 and argue as Theorems 3.5 and 3.13, we can study the variational inequality problem over split fixed point of three finite families of demicontractive mappings.

Theorem 3.19. Let $\mathrm{V}_{i}: \mathrm{H}_{1} \rightarrow \mathrm{H}_{1}$ be $\mathrm{L}_{i}$-Lipschitz continuous, $\mathrm{F}_{i}: \mathrm{H}_{1} \rightarrow \mathrm{H}_{1}$ be $\mathrm{\kappa}_{\mathrm{i}}$-Lipschitz continuous and $\eta_{i}$-strongly monotone with $\mathrm{k}_{i}>0$, and $\eta_{i}>0$. For each $i \in\{1,2, \ldots, \mathrm{m}\}, j \in\{1,2, \ldots, \ell\}, \mathrm{k} \in\{1,2, \ldots, \mathrm{s}\}$, let

(i) $\mathrm{M}_{\mathrm{i}}: \mathrm{H}_{1} \rightarrow \mathrm{H}_{1}$ be a demiclosed $\sigma_{i}$-demicontractive;

(ii) $\mathrm{Q}_{\mathrm{j}}: \mathrm{H}_{2} \rightarrow \mathrm{H}_{2}$ be a demiclosed $\mathrm{r}_{\mathrm{j}}$-demicontractive mapping;

(iii) $\mathrm{G}_{\mathrm{k}}: \mathrm{H}_{3} \rightarrow \mathrm{H}_{3}$ be a demiclosed $\delta_{\mathrm{k}}$-demicontractive mapping.

Let

(i) $M_{i} \lambda_{i}=\left(1-\lambda_{i}\right) I_{1}+\lambda_{i} M_{i}$ for $\lambda_{i} \in\left(0,1-\sigma_{i}\right)$;

(ii) $Q_{j} \beta_{j}=\left(1-\beta_{j}\right) I_{2}+\beta_{j} Q_{j}$ for $\beta_{j} \in\left(0,1-r_{j}\right)$;

(iii) $G_{k \eta_{k}}=\left(1-\eta_{k}\right) I_{3}+\eta_{k} G_{k}$ for $\eta_{k} \in\left(0,1-\delta_{k}\right)$.

Let $\left(\zeta_{1}, \zeta_{2}, \ldots, \zeta_{m}\right) \in \Delta_{m},\left(\theta_{1}, \theta_{2}, \ldots, \theta_{\ell}\right) \in \Delta_{\ell},\left(\omega_{1}, \omega_{2}, \ldots, \omega_{s}\right) \in \Delta_{s}$. Suppose that

$$
\Lambda=\left\{(x, x, x): x \in H_{1}, x \in \bigcap_{i=1}^{m} \operatorname{Fix}\left(M_{i}\right), B_{1}(x) \in \bigcap_{j=1}^{\ell} \operatorname{Fix}\left(Q_{j}\right), B_{2}(x) \in \bigcap_{k=1}^{s} \operatorname{Fix}\left(G_{k}\right)\right\} \neq \emptyset .
$$

Let $x_{1} \in \mathrm{H}_{1}, \mathrm{y}_{1} \in \mathrm{H}_{1}, z_{1} \in \mathrm{H}_{1}$, and let the sequences $\left\{\left(x_{n}, y_{n}, z_{n}\right)\right\}_{n} \in \mathbb{N}$ be defined by

(i) $x_{n+1}=\alpha_{n} \gamma V_{1}\left(x_{n}\right)+\left(I_{1}-\mu \alpha_{n} F_{1}\right) \sum_{i=1}^{m} \zeta_{i} M_{i} \lambda_{i}\left(x_{n}-\frac{\xi}{3}\left(2 x_{n}-y_{n}-z_{n}\right)\right)$ for all $n \in \mathbb{N}$;

(ii) $y_{n+1}=\alpha_{n} \gamma V_{2}\left(y_{n}\right)+\left(I_{1}-\mu \alpha_{n} F_{2}\right) \sum_{j=1}^{\ell} \theta_{j}\left(I_{1}-\frac{1}{\left\|B_{1}\right\|^{2}} B_{1}^{*}\left(I_{2}-Q_{j} \beta_{j}\right) B_{1}\right)\left(y_{n}-\frac{\xi}{3}\left(2 y_{n}-x_{n}-z_{n}\right)\right)$ for all $n \in \mathbb{N}$;

(iii) $z_{n+1}=\alpha_{n} \gamma V_{3}\left(z_{n}\right)+\left(I_{1}-\mu \alpha_{n} F_{3}\right) \sum_{k=1}^{s} \omega_{k}\left(I_{1}-\frac{1}{\left\|B_{2}\right\|^{2}} B_{2}^{*}\left(I_{3}-G_{k \eta_{k}}\right) B_{2}\right)\left(z_{n}-\frac{\xi}{3}\left(2 z_{n}-x_{n}-y_{n}\right)\right)$ for all $n \in \mathbb{N}$.

Then $\lim _{n \rightarrow \infty}\left(x_{n}, y_{n}, z_{n}\right) \in V I(\mu F-\gamma V, \Lambda)$.

Remark 3.20. Theorem 3.19 improves and generalizes [24, Theorem 3.2]. In [24, Theorem 3.2], the authors studied multiple sets split fixed point of demicontractive mappings and quasi-nonexpansive mappings.

\section{Variational inequality over split equality solutions for finite families of nonlinear mappings}

Let $B: H_{1} \multimap H_{1}$ be a multivalued mapping. The effective domain of $B$ is denoted by $D(B)$, that is, $D(B)=\left\{x \in H_{1}: B x \neq \emptyset\right\}$. We say $B: H_{1} \multimap H_{1}$ is monotone on $H_{1}$ if $\langle x-y, u-v\rangle \geqslant 0$ for all $x, y \in D(B), u \in B x$, and $v \in B y$. $B$ is maximal monotone on $H_{1}$ if $B$ is a monotone operator on $H_{1}$ and its graph is not properly contained in the graph of any other monotone operator on $\mathrm{H}_{1}$. For a maximal monotone operator $B: H_{1} \multimap H_{1}$ and $r>0$, we may define a single-valued mapping $J_{r}^{B}: H_{1} \rightarrow D(B)$ by $\mathrm{J}_{\mathrm{r}}^{\mathrm{B}}=(\mathrm{I}+\mathrm{rB})^{-1}$, and it is called the resolvent mapping of $\mathrm{B}$ for $r$.

For each $i \in\{1,2, \ldots, m\}$, let $C_{i}$ be a closed convex subset of $H_{1}$, let $M_{1 i}: H_{1} \multimap H_{1}$ be a maximum monotone multivalued mapping such that $\mathrm{D}\left(\mathrm{M}_{1 i}\right) \subset \mathrm{C}_{i}, \mathrm{~L}_{1 i}: \mathrm{C}_{i} \rightarrow \mathrm{H}_{1}$ be a $\gamma_{1 i}$-inverse strongly monotone 
operator, $h_{1 i} \in \Gamma_{0}\left(H_{1}\right), g_{1 i} \in \Gamma_{0}\left(H_{1}\right)$, and let $g_{1 i}$ be Fréchet differentiable with $\sigma_{1 i}$-Lipschitz continuous Fréchet derivative $\nabla g_{1 i}$.

For each $j \in\{1,2, \ldots, \ell\}$, let $D_{j}$ be a closed convex subset of $H_{2}, M_{2 j}: H_{2} \multimap H_{2}$ be a maximum monotone operator such that $\mathrm{D}\left(M_{2 j}\right) \subset \mathrm{D}_{j}, \mathrm{~L}_{2 j}: \mathrm{D}_{j} \rightarrow \mathrm{H}_{2}$ be a $\gamma_{2 j}$-inverse strongly monotone operator, $h_{2 j} \in \Gamma_{0}\left(H_{2}\right), g_{2 j} \in \Gamma_{0}\left(H_{2}\right)$, and let $g_{2 j}$ be Fréchet differentiable with $\sigma_{2 j}$-Lipschitz continuous Fréchet derivative $\nabla g_{2 j}$. For each $k \in\{1,2, \ldots, s\}$, let $E_{k}$ be a closed convex subset of $H_{3}, M_{3 k}: H_{3} \multimap H_{3}$ be a maximum monotone operator such that $D\left(M_{3 k}\right) \subset E_{k}, L_{3 k}: E_{k} \rightarrow H_{3}$ be a $\gamma_{3 k}$-inverse strongly monotone operator, $h_{3 k} \in \Gamma_{0}\left(H_{3}\right), g_{3 k} \in \Gamma_{0}\left(H_{3}\right)$, and let $g_{3 k}$ be Fréchet differentiable with $\sigma_{3 k}$-Lipschitz continuous $\nabla \mathrm{g}_{3 \mathrm{k}}$. For each $\mathrm{k} \in\{1,2, \ldots, \mathrm{s}\}$, let $\mathrm{G}_{\mathrm{k}}: \mathrm{H}_{3} \rightarrow \mathrm{H}_{3}$ be a demiclosed $\delta_{\mathrm{k}}$-demicontractive mapping. Throughout this section we use these notations and assumptions unless specified otherwise.

Theorem 4.1. Let $\left(\zeta_{1}, \zeta_{2}, \ldots, \zeta_{m}\right) \in \Delta_{m},\left(\theta_{1}, \theta_{2}, \ldots, \theta_{\ell}\right) \in \Delta_{\ell},\left(\omega_{1}, \omega_{2}, \ldots, \omega_{s}\right) \in \Delta_{s}$ and let $\zeta>0$. Suppose that

$$
\begin{gathered}
\Lambda=\left\{(x, y, z) \in \bigotimes_{1 \leqslant i \leqslant 3} H_{i}: x \in \bigcap_{i=1}^{m}\left(M_{1 i}+L_{1 i}\right)^{-1} 0, z \in \bigcap_{k=1}^{s} \operatorname{Fix}\left(G_{k}\right), y \in \bigcap_{j=1}^{\ell}\left(M_{2 j}+L_{2 j}\right)^{-1} 0,\right. \\
\left.A_{1}(x)=A_{2}(y)=A_{3}(z)\right\} \neq \emptyset .
\end{gathered}
$$

Let $x_{1} \in \mathrm{H}_{1}, \mathrm{y}_{1} \in \mathrm{H}_{2}, z_{1} \in \mathrm{H}_{3}$, and let the sequences $\left\{\left(x_{\mathfrak{n}}, y_{n}, z_{n}\right)\right\}_{\mathfrak{n} \in \mathbb{N}}$ be defined by

(i) $x_{n+1}=\alpha_{n} \gamma V_{1}\left(x_{n}\right)+\left(I_{1}-\mu \alpha_{n} F_{1}\right) \sum_{i=1}^{m} \zeta_{i} J_{\zeta}^{M_{1 i}}\left(I_{1}-\zeta L_{1 i}\right)\left(x_{n}-\frac{\xi}{3} A_{1}^{*}\left(2 A_{1}\left(x_{n}\right)-A_{2}\left(y_{n}\right)-A_{3}\left(z_{n}\right)\right)\right)$ for all $\mathrm{n} \in \mathbb{N}$;

(ii) $y_{n+1}=\alpha_{n} \gamma V_{2}\left(y_{n}\right)+\left(I_{2}-\mu \alpha_{n} F_{2}\right) \sum_{j=1}^{\ell} \theta_{j} J_{\zeta}^{M_{2 j}}\left(I_{2}-\zeta L_{2 j}\right)\left(y_{n}-\frac{\xi}{3} A_{2}^{*}\left(2 A_{2}\left(y_{n}\right)-A_{1}\left(x_{n}\right)-A_{3}\left(z_{n}\right)\right)\right)$ for all $\mathrm{n} \in \mathbb{N}$;

(iii) $z_{n+1}=\alpha_{n} \gamma V_{3}\left(z_{n}\right)+\left(I_{3}-\mu \alpha_{n} F_{3}\right) \sum_{k=1}^{s} \omega_{k} G_{k \eta_{k}}\left(z_{n}-\frac{\xi}{3} A_{3}^{*}\left(2 A_{3}\left(z_{n}\right)-A_{1}\left(x_{n}\right)-A_{2}\left(y_{n}\right)\right)\right)$ for all $n \in$ $\mathbb{N}$.

Then $\lim _{n \rightarrow \infty}\left(x_{n}, y_{n}, z_{n}\right) \in V I(\mu F-\gamma V, \Lambda)$.

Proof. Argue as [25, Theorem 4.1], we see that $J_{\zeta}^{M_{1 i}}\left(I_{1}-\zeta L_{1 i}\right)$ and $J_{\zeta}^{M_{2 j}}\left(I_{2}-\zeta L_{2 j}\right)$ are averaged for each $i \in\{1,2, \ldots, m\}$ and each $j \in\{1,2, \ldots, \ell\}$.

It is easy to see that

(i) $\operatorname{Fix}\left(J_{\zeta}^{M_{1 i}}\left(I_{1}-\zeta L_{1 i}\right)\right)=\left(M_{1 i}+L_{1 i}\right)^{-1} 0$;

(ii) $\operatorname{Fix}\left(J_{\zeta}^{M_{2 j}}\left(I_{2}-\zeta L_{2 j}\right)\right)=\left(M_{2 j}+L_{2 j}\right)^{-1} 0$.

By Proposition 2.2,

(i) $J_{\zeta}^{M_{1 i}}\left(I_{1}-\zeta L_{1 i}\right)$ is a $\lambda_{i}$-strongly quasi-nonexpansive mapping for some $\lambda_{i}>0$;

(ii) $J_{\zeta}^{M_{2 j}}\left(I_{2}-\zeta L_{2 j}\right)$ is a $\beta_{j}$-strongly quasi-nonexpansive mapping for some $\beta_{j}>0$.

For each $i \in\{1,2, \ldots, m\}$, and each $j \in\{1,2, \ldots, \ell\}$, since $J_{\zeta}^{M_{1 i}}\left(I_{1}-\zeta L_{1 i}\right)$ and $J_{\zeta}^{M_{2 j}}\left(I_{2}-\zeta L_{2 j}\right)$ are averaged, $\mathrm{J}_{\zeta}^{M_{1 i}}\left(\mathrm{I}_{1}-\zeta \mathrm{L}_{1 i}\right)$ and $\mathrm{J}_{\zeta}^{\mathrm{M}_{2 j}}\left(\mathrm{I}_{2}-\zeta \mathrm{L}_{2 j}\right)$ are nonexpansive. By Lemma 2.1, $\mathrm{J}_{\zeta}^{M_{1 i}}\left(\mathrm{I}_{1}-\zeta \mathrm{L}_{1 i}\right)$ and $\mathrm{J}_{\zeta}^{\mathrm{M}_{2 j}}\left(\mathrm{I}_{2}-\zeta \mathrm{L}_{2 \mathrm{j}}\right)$ are demiclosed.

It follows from Lemma 2.3 for each $k \in\{1,2, \ldots, s\}, \eta_{k} \in\left(0,1-\delta_{k}\right)$ that $G_{k \eta_{k}}$ is a demiclosed $\left(1-\delta_{k}-\right.$ $\eta_{k}$ )-strongly quasi-nonexpansive mapping. Let

$$
\Omega=\left\{x \in \bigcap_{i=1}^{m} \operatorname{Fix}\left(J_{\zeta}^{M_{1 i}}\left(I_{1}-\zeta L_{1 i}\right)\right), z \in \bigcap_{k=1}^{s} \operatorname{Fix}\left(G_{k \eta_{k}}\right), y \in \bigcap_{j=1}^{\ell} \operatorname{Fix}\left(J_{\zeta}^{M_{2 j}}\left(I_{2}-\zeta L_{2 j}\right)\right), A_{1}(x)=A_{2}(y)=A_{3}(z)\right\} .
$$

It is easy to see that $\Lambda=\Omega \neq \emptyset$ and Theorem 4.1 follows from Theorem 3.3. 
Theorem 4.2. Let $\left(\zeta_{1}, \zeta_{2}, \ldots, \zeta_{\mathrm{m}}\right) \in \Delta_{\mathrm{m}},\left(\theta_{1}, \theta_{2}, \ldots, \theta_{\ell}\right) \in \Delta_{\ell},\left(\omega_{1}, \omega_{2}, \ldots, \omega_{s}\right) \in \Delta_{s}$, let $\mathrm{V}_{i}: \mathrm{H}_{1} \rightarrow \mathrm{H}_{1}$ be $\mathrm{L}_{\mathrm{i}}$-Lipschitz continuous, $\mathrm{F}_{\mathrm{i}}: \mathrm{H}_{1} \rightarrow \mathrm{H}_{1}$ be $\mathrm{K}_{\mathrm{i}}$-Lipschitz continuous and $\eta_{\mathrm{i}}$-strongly monotone with $\mathrm{K}_{\mathrm{i}}>0$, and $\eta_{i}>0$, and let $\mathrm{k}>0$. Suppose that

$$
\Lambda=\left\{(x, x, x): x \in \mathrm{H}_{1}, x \in \bigcap_{i=1}^{m}\left(M_{1 i}+L_{1 i}\right)^{-1} 0, B_{1}(x) \in \bigcap_{j=1}^{\ell}\left(M_{2 j}+L_{2 j}\right)^{-1} 0, B_{2}(x) \in \bigcap_{k=1}^{s} \operatorname{Fix}\left(G_{k}\right)\right\} \neq \emptyset .
$$

Let $x_{1} \in \mathrm{H}_{1}, \mathrm{y}_{1} \in \mathrm{H}_{1}, z_{1} \in \mathrm{H}_{1}$, and let the sequences $\left\{\left(x_{n}, y_{n}, z_{n}\right)\right\}_{n \in \mathbb{N}}$ be defined by

(i) $x_{n+1}=\alpha_{n} \gamma V_{1}\left(x_{n}\right)+\left(I_{1}-\mu \alpha_{n} F_{1}\right) \sum_{i=1}^{m} \zeta_{i} J_{k}^{M_{1 i}}\left(I_{1}-k L_{1 i}\right)\left(x_{n}-\frac{\xi}{3}\left(2 x_{n}-y_{n}-z_{n}\right)\right)$ for all $n \in \mathbb{N}$;

(ii) $y_{n+1}=\alpha_{n} \gamma V_{2}\left(y_{n}\right)+\left(I_{1}-\mu \alpha_{n} F_{2}\right) \sum_{j=1}^{\ell} \theta_{j}\left(I_{1}-\frac{1}{\left\|B_{1}\right\|^{2}} B_{1}^{*}\left(I_{2}-\left(J_{k}^{M_{2 j}}\left(I_{2}-\kappa L_{2 j}\right)\right) B_{1}\right)\right)\left(y_{n}-\frac{\xi}{3}\left(y_{n}-x_{n}-\right.\right.$ $z_{\mathrm{n}}$ )) for all $\mathrm{n} \in \mathbb{N}$;

(iii) $z_{n+1}=\alpha_{n} \gamma V_{3}\left(z_{n}\right)+\left(I_{1}-\mu \alpha_{n} F_{3}\right) \sum_{k=1}^{s} \omega_{k}\left(I_{1}-\frac{1}{\left\|B_{2}\right\|^{2}} B_{2}^{*}\left(I_{3}-G_{k \eta_{k}}\right) B_{2}\right)\left(z_{n}-\frac{\xi}{3}\left(2 z_{n}-x_{n}-y_{n}\right)\right)$ for all $\mathrm{n} \in \mathbb{N}$.

Then $\lim _{n \rightarrow \infty}\left(x_{n}, y_{n}, z_{n}\right) \in V I(\mu F-\gamma V, \Lambda)$.

Proof. Theorem 3.5 shows that for $\eta_{k} \in\left(0,1-\delta_{k}\right), G_{k \eta_{k}}$ is a demiclosed $\left(1-\delta_{k}-\eta_{k}\right)$-strongly quasinonexpansive mapping. In Theorem 4.1, we show that

(i) $J_{k}^{M_{1 i}}\left(I_{1}-k L_{1 i}\right)$ is a $\lambda_{i}$-strongly quasi-nonexpansive mapping for some $\lambda_{i}>0$;

(ii) $J_{K}^{M_{2 j}}\left(I_{2}-\kappa L_{2 j}\right)$ is a $\beta_{j}$-strongly quasi-nonexpansive mapping for some $\beta_{j}>0$.

Let

(i) $\mathrm{U}_{j}=\left(\mathrm{I}_{1}-\frac{1}{\left\|\mathrm{~B}_{1}\right\|^{2}} \mathrm{~B}_{1}^{*}\left(\mathrm{I}_{2}-\mathrm{J}_{\mathrm{k}}^{\mathrm{M}_{2 j}}\left(\mathrm{I}_{2}-\kappa \mathrm{L}_{2 j}\right)\right) \mathrm{B}_{1}\right)$;

(ii) $W_{k \eta_{k}}=\left(I_{1}-\frac{1}{\left\|B_{2}\right\|^{2}} B_{2}^{*}\left(I_{3}-G_{k \eta_{k}}\right) B_{2}\right)$.

By Proposition 2.8, for $\eta_{k} \in\left(0,1-\delta_{k}\right)$,

(i) $\operatorname{Fix}\left(\mathrm{U}_{j}\right)=\mathrm{B}_{1}^{-1} \operatorname{Fix}\left(\mathrm{J}_{\mathrm{k}}^{\mathrm{M}_{2 j}}\left(\mathrm{I}_{2}-\mathrm{kL}_{2 j}\right)\right)$ and $\operatorname{Fix}\left(\mathrm{W}_{\mathrm{k} \eta_{k}}\right)=\mathrm{B}_{2}^{-1} \operatorname{Fix}\left(\mathrm{G}_{\mathrm{k}}\right)$;

(ii) $\mathrm{U}_{\mathrm{j}}: \mathrm{H}_{1} \rightarrow \mathrm{H}_{1}$ is a demiclosed $\beta_{\mathrm{j}}$-strongly quasi-nonexpansive mapping, and $W_{\mathrm{k}} \eta_{\mathrm{k}}: \mathrm{H}_{1} \rightarrow \mathrm{H}_{1}$ is a demiclosed $\left(1-\delta_{k}-\eta_{k}\right)$-strongly quasi-nonexpansive mapping.

Let

$$
\Omega=\left\{(x, x, x): x \in H_{1}, x \in \bigcap_{i=1}^{m} \operatorname{Fix}\left(J_{k}^{M_{1 i}}\left(I_{1}-k L_{1 i}\right)\right), x \in \bigcap_{j=1}^{\ell} \operatorname{Fix}\left(U_{j}\right), x \in \bigcap_{k=1}^{s} \operatorname{Fix}\left(W_{k \eta_{k}}\right)\right\} .
$$

It is easy to see that $\Omega=\Lambda \neq \emptyset$. Then Theorem 4.2 follows from Theorem 3.3.

Remark 4.3. In [21] the authors introduced an iteration to study the following problem:

Find $x \in M^{-1} 0$ such that $\mathrm{L} x \in \operatorname{Fix}(T)$,

where $M: H_{1} \multimap H_{1}$ is a maximum monotone operator, and $T: H_{2} \rightarrow H_{2}$ is a nonexpansive operator. Theorems 4.1 and 4.2 improve and generalize [21, Theorems 4.2 and 4.3]. In [21, Theorems 4.2 and 4.3], the authors established weak convergence theorems of this problem .

Theorem 4.4. Let $\left(\zeta_{1}, \zeta_{2}, \ldots, \zeta_{\mathrm{m}}\right) \in \Delta_{\mathrm{m}},\left(\theta_{1}, \theta_{2}, \ldots, \theta_{\ell}\right) \in \Delta_{\ell},\left(\omega_{1}, \omega_{2}, \ldots, \omega_{s}\right) \in \Delta_{s}$, let $\mathrm{V}_{i}: \mathrm{H}_{1} \rightarrow \mathrm{H}_{1}$ be $\mathrm{L}_{i}$-Lipschitz continuous, $\mathrm{F}_{i}: \mathrm{H}_{1} \rightarrow \mathrm{H}_{1}$ be $\mathrm{\kappa}_{\mathrm{i}}$-Lipschitz continuous and $\eta_{i}$-strongly monotone with $\mathrm{K}_{i}>0$, and $\eta_{i}>0$, and let $\mathrm{K}>0$. Suppose that

$$
\left.\Lambda=\left\{(x, x, x): x \in \mathrm{H}_{1}, x \in \bigcap_{i=1}^{\mathrm{m}}\left(\mathrm{M}_{1 \mathrm{i}}+\mathrm{L}_{1 i}\right)^{-1} 0, \mathrm{~B}_{1}(\mathrm{x}) \in \bigcap_{\mathrm{j}=1}^{\ell}\left(\mathrm{M}_{2 j}+\mathrm{L}_{2 j}\right)^{-1} 0, \mathrm{~B}_{2}(\mathrm{x}) \in \bigcap_{\mathrm{k}=1}^{s}\left(\mathrm{M}_{3 \mathrm{k}}+\mathrm{L}_{3 \mathrm{k}}\right)^{-1}\right)\right\} \neq \emptyset .
$$

Let $\mathrm{x}_{1} \in \mathrm{H}_{1}, \mathrm{y}_{1} \in \mathrm{H}_{1}, z_{1} \in \mathrm{H}_{1}$, and let the sequences $\left\{\left(x_{n}, y_{n}, z_{n}\right)\right\}_{n \in \mathbb{N}}$ be defined by 
(i) $x_{n+1}=\alpha_{n} \gamma V_{1}\left(x_{n}\right)+\left(I_{1}-\mu \alpha_{n} F_{1}\right) \sum_{i=1}^{m} \zeta_{i} J_{k}^{M_{1 i}}\left(I_{1}-k L_{1 i}\right)\left(x_{n}-\frac{\xi}{3}\left(2 x_{n}-y_{n}-z_{n}\right)\right)$ for all $n \in \mathbb{N}$;

(ii) $y_{n+1}=\alpha_{n} \gamma V_{2}\left(y_{n}\right)+\left(I_{1}-\mu \alpha_{n} F_{2}\right) \sum_{j=1}^{\ell} \theta_{2 j}\left(I_{1}-\frac{1}{\left\|B_{1}\right\|^{2}} B_{1}^{*}\left(I_{2}-\left(J_{k}^{M_{2 j}}\left(I_{2}-k L_{2 j}\right)\right) B_{1}\right)\right)\left(y_{n}-\frac{\xi}{3}\left(y_{n}-x_{n}-\right.\right.$ $z_{n}$ )) for all $\mathrm{n} \in \mathbb{N}$;

(iii) $z_{n+1}=\alpha_{n} \gamma V_{3}\left(z_{n}\right)+\left(I_{1}-\mu \alpha_{n} F_{3}\right) \sum_{k=1}^{s} \omega_{k}\left(I_{1}-\frac{1}{\left\|B_{2}\right\|^{2}} B_{2}^{*}\left(I_{3}-J_{k}^{M_{3 k}}\left(I_{3}-\kappa L_{3 k}\right)\right) B_{2}\right)\left(z_{n}-\frac{\xi}{3}\left(2 z_{n}-x_{n}-\right.\right.$ $\mathrm{y}_{\mathrm{n}}$ )) for all $\mathrm{n} \in \mathbb{N}$.

Then $\lim _{n \rightarrow \infty}\left(x_{n}, y_{n}, z_{n}\right) \in V I(\mu F-\gamma V, \Lambda)$.

Proof. Theorem 4.1 shows that

(i) $J_{k}^{M_{1 i}}\left(I_{1}-\kappa L_{1 i}\right)$ is a $\lambda_{i}$-strongly quasi-nonexpansive mapping for some $\lambda_{i}>0$;

(ii) $J_{K}^{M_{2 j}}\left(I_{2}-\kappa L_{2 j}\right)$ is a $\beta_{j}$-strongly quasi-nonexpansive mapping for some $\beta_{j}>0$;

(iii) $\mathrm{J}_{k}^{M_{3 k}}\left(I_{3}-k L_{3 k}^{k}\right)$ is a $\delta_{k}$-strongly quasi-nonexpansive mapping for some $\delta_{k}>0$.

Let

(i) $\mathrm{M}_{\mathrm{i}}=\mathrm{J}_{\mathrm{K}}^{\mathrm{M}_{1 i}}\left(\mathrm{I}_{1}-\mathrm{k} \mathrm{L}_{1 \mathrm{i}}\right)$;

(ii) $Q_{j}=\left(I_{1}-\frac{1}{\left\|B_{1}\right\|^{2}} B_{1}^{*}\left(I_{2}-J_{\kappa}^{M_{2 j}}\left(I_{2}-\kappa L_{2 j}\right)\right) B_{1}\right)$;

(iii) $W_{k}=\left(I_{1}-\frac{1}{\left\|B_{2}\right\|^{2}} B_{2}^{*}\left(I_{3}-J_{k}^{M_{3 k}}\left(I_{3}-k L_{3 k}\right)\right) B_{2}\right)$.

By Proposition 2.8,

(i) Fix $\left(M_{i}\right)=H_{1} \rightarrow H_{1}$ is a demiclosed $\lambda_{i}$-strongly quasi-nonexpansive mapping, and $\operatorname{Fix}\left(M_{i}\right)=$ $\left(\left(M_{1 i}+L_{1 i}\right)^{-1} 0\right)$

(ii) $Q_{j}: H_{1} \rightarrow H_{1}$ is a demiclosed $\beta_{j}$-strongly quasi-nonexpansive mapping, and $\operatorname{Fix}\left(Q_{j}\right)=\left(B_{1}^{-1}\left(M_{2 j}+\right.\right.$ $\left.\mathrm{L}_{2 j}\right)^{-1} 0$ );

(iii) and $W_{k}: H_{1} \rightarrow H_{1}$ is a demiclosed $\delta_{k}$-strongly quasi-nonexpansive mapping, and Fix $\left(W_{k}\right)=$ $\left(B_{2}^{-1}\left(M_{3 k}+L_{3 k}\right)^{-1} 0\right)$.

Let

$$
\Omega=\left\{(x, x, x): x \in H_{1}, x \in \bigcap_{i=1}^{m} \operatorname{Fix}\left(M_{i}\right), x \in \bigcap_{j=1}^{\ell} \operatorname{Fix}\left(Q_{j}\right), x \in \bigcap_{k=1}^{s} \operatorname{Fix}\left(W_{k}\right)\right\} .
$$

It is easy to see that $\Omega=\Lambda \neq \emptyset$. Then Theorem 4.4 follows from Corollary 3.4.

Theorem 4.5. Let $\left(\zeta_{1}, \zeta_{2}, \ldots, \zeta_{m}\right) \in \Delta_{m},\left(\theta_{1}, \theta_{2}, \ldots, \theta_{\ell}\right) \in \Delta_{\ell},\left(\omega_{1}, \omega_{2}, \ldots, \omega_{s}\right) \in \Delta_{s}$, and let $\mathrm{k}>0$. Suppose that

$$
\begin{gathered}
\Lambda=\left\{(x, y, z) \in \bigotimes_{1 \leqslant i \leqslant 3} H_{i}: x \in H_{1}, x \in \bigcap_{i=1}^{m}\left(M_{1 i}+L_{1 i}\right)^{-1} 0, z \in \bigcap_{k=1}^{s}\left(M_{3 k}+L_{3 k}\right)^{-1} 0, y \in \bigcap_{j=1}^{\ell}\left(M_{2 j}+L_{2 j}\right)^{-1} 0,\right. \\
\left.A_{1}(x)=A_{2}(y)=A_{3}(z)\right\} \neq \emptyset .
\end{gathered}
$$

Let $x_{1} \in \mathrm{H}_{1}, \mathrm{y}_{1} \in \mathrm{H}_{2}, z_{1} \in \mathrm{H}_{3}$, and let the sequences $\left\{\left(x_{n}, y_{n}, z_{n}\right)\right\}_{n} \in \mathbb{N}$ be defined by

(i) $x_{n+1}=\alpha_{n} \gamma V_{1}\left(x_{n}\right)+\left(I_{1}-\mu \alpha_{n} F_{1}\right) \sum_{i=1}^{m} \zeta_{i} J_{k}^{M_{1 i}}\left(I_{1}-\kappa L_{1 i}\right)\left(x_{n}-\frac{\xi}{3} A_{1}^{*}\left(2 A_{1}\left(x_{n}\right)-A_{2}\left(y_{n}\right)-A_{3}\left(z_{n}\right)\right)\right)$ for all $\mathrm{n} \in \mathbb{N}$;

(ii) $y_{n+1}=\alpha_{n} \gamma V_{2}\left(y_{n}\right)+\left(I_{2}-\mu \alpha_{n} F_{2}\right) \sum_{j=1}^{\ell} \theta_{j} J_{k}^{M_{2 j}}\left(I_{2}-k L_{2 j}\right)\left(y_{n}-\frac{\xi}{3} A_{2}^{*}\left(2 A_{2}\left(y_{n}\right)-A_{1}\left(x_{n}\right)-A_{3}\left(z_{n}\right)\right)\right)$ for all $\mathrm{n} \in \mathbb{N}$;

(iii) $z_{n+1}=\alpha_{n} \gamma V_{3}\left(z_{n}\right)+\left(I_{3}-\mu \alpha_{n} F_{3}\right) \sum_{k=1}^{s} \omega_{k} J_{k}^{M_{3 k}}\left(I_{3}-\kappa L_{3 k}^{k}\right)\left(z_{n}-\frac{\xi}{3} A_{3}^{*}\left(2 A_{3}\left(z_{n}\right)-A_{1}\left(x_{n}\right)-A_{2}\left(y_{n}\right)\right)\right)$ for all $\mathrm{n} \in \mathbb{N}$.

Then $\lim _{n \rightarrow \infty}\left(x_{n}, y_{n}, z_{n}\right) \in V I(\mu F-\gamma V, \Lambda)$. 
Proof. We apply Theorem 4.1 and argue as in Theorem 4.4, we can prove Theorem 4.5.

Remark 4.6. Theorems 4.1 and 4.5 improve and generalize [23, Theorem 4.2].

Corollary 4.7. In Theorem 4.4, let $\mathrm{H}_{1}=\mathrm{H}_{2}=\mathrm{H}_{3}=\mathrm{H}_{4}, \mathrm{I}_{1}=\mathrm{I}_{2}=\mathrm{I}_{3},\left(\zeta_{1}, \zeta_{2}, \ldots, \zeta_{\mathrm{m}}\right) \in \Delta_{\mathrm{m}},\left(\theta_{1}, \theta_{2}, \ldots, \theta_{\ell}\right) \in$ $\Delta_{\ell}$, and $\left(\omega_{1}, \omega_{2}, \ldots, \omega_{s}\right) \in \Delta_{s}$. Suppose that

$$
\left.\Lambda=\left\{(x, x, x): x \in H_{1}, x \in \bigcap_{i=1}^{m}\left(M_{1 i}+L_{1 i}\right)^{-1} 0 \bigcap \bigcap_{j=1}^{\ell}\left(M_{2 j}+L_{2 j}\right)^{-1} 0 \bigcap_{k=1}^{s}\left(M_{3 k}+L_{3 k}\right)^{-1} 0\right)\right\} \neq \emptyset .
$$

Let $x_{1} \in H_{1}, y_{1} \in H_{1}, z_{1} \in H_{1}$, and let the sequences $\left\{\left(x_{n}, y_{n}, z_{n}\right)\right\}_{\mathfrak{n} \in \mathbb{N}}$ be defined by

(i) $x_{n+1}=\alpha_{n} \gamma V_{1}\left(x_{n}\right)+\left(I_{1}-\mu \alpha_{n} F_{1}\right) \sum_{i=1}^{m} \zeta_{i} J_{k}^{M_{1 i}}\left(I_{1}-\kappa L_{1 i}\right)\left(x_{n}-\frac{\xi}{3}\left(2 x_{n}-y_{n}-z_{n}\right)\right)$ for all $n \in \mathbb{N}$;

(ii) $y_{n+1}=\alpha_{n} \gamma V_{2}\left(y_{n}\right)+\left(I_{1}-\mu \alpha_{n} F_{2}\right) \sum_{j=1}^{\ell} \theta_{j} J_{k}^{M_{2 j}}\left(I_{1}-k L_{2 j}\right)\left(y_{n}-\frac{\xi}{3}\left(y_{n}-x_{n}-z_{n}\right)\right)$ for all $n \in \mathbb{N}$;

(iii) $z_{n+1}=\alpha_{n} \gamma V_{3}\left(z_{n}\right)+\left(I_{1}-\mu \alpha_{n} F_{3}\right) \sum_{k=1}^{s} \omega_{k} J_{k}^{M_{3 k}}\left(I_{1}-k L_{3 k}\right)\left(z_{n}-\frac{\xi}{3}\left(2 z_{n}-x_{n}-y_{n}\right)\right)$ for all $n \in \mathbb{N}$.

Then $\lim _{n \rightarrow \infty}\left(x_{n}, y_{n}, z_{n}\right) \in V I(\mu F-\gamma V, \Lambda)$.

Proof. Let $\mathrm{B}_{1}=\mathrm{I}_{1}=\mathrm{B}_{2}=\mathrm{I}_{2}=\mathrm{I}_{3}$ in Theorem 4.4, then $\left\|\mathrm{B}_{1}\right\|=\left\|\mathrm{B}_{2}\right\|=1$ and Corollary 4.7 follows from Theorem 4.4.

Theorem 4.8. Let $\left(\zeta_{1}, \zeta_{2}, \ldots, \zeta_{\mathrm{m}}\right) \in \Delta_{\mathrm{m}},\left(\theta_{1}, \theta_{2}, \ldots, \theta_{\ell}\right) \in \Delta_{\ell},\left(\omega_{1}, \omega_{2}, \ldots, \omega_{s}\right) \in \Delta_{s}$, let $\mathrm{V}_{i}: \mathrm{H}_{1} \rightarrow \mathrm{H}_{1}$ be $\mathrm{L}_{\mathrm{i}}$-Lipschitz continuous, $\mathrm{F}_{\mathrm{i}}: \mathrm{H}_{1} \rightarrow \mathrm{H}_{1}$ be $\mathrm{\kappa}_{i}$-Lipschitz continuous and $\eta_{i}$-strongly monotone with $\mathrm{K}_{\mathrm{i}}>0$, and $\eta_{i}>0$. Suppose that

$$
\Lambda=\left\{(x, x, x): x \in \mathrm{H}_{1}, x \in \bigcap_{i=1}^{m} \mathrm{C}_{i}, \mathrm{~B}_{1}(x) \in \bigcap_{j=1}^{\ell} \mathrm{D}_{j}, \mathrm{~B}_{2}(x) \in \bigcap_{\mathrm{k}=1}^{s} \operatorname{Fix}\left(\mathrm{G}_{\mathrm{k}}\right)\right\} \neq \emptyset .
$$

Let $\mathrm{x}_{1} \in \mathrm{H}_{1}, \mathrm{y}_{1} \in \mathrm{H}_{1}, z_{1} \in \mathrm{H}_{1}$, and let the sequences $\left\{\left(\mathrm{x}_{\mathrm{n}}, \mathrm{y}_{\mathrm{n}}, z_{\mathrm{n}}\right)\right\}_{\mathfrak{n} \in \mathbb{N}}$ be defined by

(i) $x_{n+1}=\alpha_{n} \gamma V_{1}\left(x_{n}\right)+\left(I_{1}-\mu \alpha_{n} F_{1}\right) \sum_{i=1}^{m} \zeta_{i} P_{C_{i}}\left(x_{n}-\frac{\xi}{3}\left(2 x_{n}-y_{n}-z_{n}\right)\right)$ for all $n \in \mathbb{N}$;

(ii) $y_{n+1}=\alpha_{n} \gamma V_{2}\left(y_{n}\right)+\left(I_{1}-\mu \alpha_{n} F_{2}\right) \sum_{j=1}^{\ell} \theta_{j}\left(I_{1}-\frac{1}{\left\|B_{1}\right\|^{2}} B_{1}^{*}\left(I_{2}-P_{D_{j}}\right) B_{1}\right)\left(y_{n}-\frac{\xi}{3}\left(y_{n}-x_{n}-z_{n}\right)\right)$ for all $\mathrm{n} \in \mathbb{N}$

(iii) $z_{n+1}=\alpha_{n} \gamma V_{3}\left(z_{n}\right)+\left(I_{1}-\mu \alpha_{n} F_{3}\right) \sum_{k=1}^{s} \omega_{k}\left(I_{1}-\frac{1}{\left\|B_{2}\right\|^{2}} B_{2}^{*}\left(I_{3}-G_{k \eta_{k}}\right) B_{2}\right)\left(z_{n}-\frac{\xi}{3}\left(2 z_{n}-x_{n}-y_{n}\right)\right)$ for all $n \in \mathbb{N}$.

Then $\lim _{n \rightarrow \infty}\left(x_{n}, y_{n}, z_{n}\right) \in V I(\mu F-\gamma V, \Lambda)$.

Proof. Let $\mathrm{L}_{1 i}=0, \mathrm{~L}_{2 j}=0, \mathrm{M}_{1 i}=\partial \iota_{\mathrm{C}_{i}}, \mathrm{M}_{2 j}=\partial \iota_{\mathrm{D}_{j}}$ in Theorem 4.2, then $\mathrm{J}_{\mathrm{K}}^{\partial \iota \mathrm{C}_{i}}=\mathrm{P}_{\mathrm{C}_{i}}, \mathrm{~J}_{\mathrm{K}}^{\partial \iota_{\mathrm{D}_{j}}}=\mathrm{P}_{\mathrm{D}_{j}}$, and theorem 4.8 follows from Theorem 4.2.

Remark 4.9. Theorem 4.8 improves and generalizes [4, Theorem 3.1]. In [4, Theorem 3.1], the authors established a strongly convergence theorem for split feasibility problem and fixed point problem of kstrictly pseudo-contractive mapping.

Corollary 4.10. Lett $\left(\zeta_{1}, \zeta_{2}, \ldots, \zeta_{\mathrm{m}}\right) \in \Delta_{\mathrm{m}},\left(\theta_{1}, \theta_{2}, \ldots, \theta_{\ell}\right) \in \Delta_{\ell},\left(\omega_{1}, \omega_{2}, \ldots, \omega_{s}\right) \in \Delta_{s}$, let $\mathrm{V}_{\mathrm{i}}: \mathrm{H}_{1} \rightarrow \mathrm{H}_{1}$ be $\mathrm{L}_{\mathrm{i}}$-Lipschitz continuous, $\mathrm{F}_{\mathrm{i}}: \mathrm{H}_{1} \rightarrow \mathrm{H}_{1}$ be $\mathrm{\kappa}_{\mathrm{i}}$-Lipschitz continuous and $\eta_{\mathrm{i}}$-strongly monotone with $\mathrm{\kappa}_{\mathrm{i}}>0$, and $\eta_{i}>0$. Suppose that

$\Lambda=\left\{(x, x, x): x \in H_{1}, x \in \bigcap_{i=1}^{m} C_{i}, B_{1}(x) \in \bigcap_{j=1}^{\ell} D_{j}, B_{2}(x) \in \bigcap_{k=1}^{s} E_{k}\right\} \neq \emptyset$.

Let $x_{1} \in H_{1}, y_{1} \in H_{1}, z_{1} \in H_{1}$, and let the sequences $\left\{\left(x_{n}, y_{n}, z_{n}\right)\right\}_{n} \in \mathbb{N}$ be defined by

(i) $x_{n+1}=\alpha_{n} \gamma V_{1}\left(x_{n}\right)+\left(I_{1}-\mu \alpha_{n} F_{1}\right) \sum_{i=1}^{m} \zeta_{i} P_{C_{i}}\left(x_{n}-\frac{\xi}{3}\left(2 x_{n}-y_{n}-z_{n}\right)\right)$ for all $n \in \mathbb{N}$; 
(ii) $y_{n+1}=\alpha_{n} \gamma V_{2}\left(y_{n}\right)+\left(I_{1}-\mu \alpha_{n} F_{2}\right) \sum_{j=1}^{\ell} \theta_{j}\left(I_{1}-\frac{1}{\left\|B_{1}\right\|^{2}} B_{1}^{*}\left(I_{1}-P_{D_{j}}\right) B_{1}\right)\left(y_{n}-\frac{\xi}{3}\left(y_{n}-x_{n}-z_{n}\right)\right)$ for all $\mathrm{n} \in \mathbb{N}$;

(iii) $z_{n+1}=\alpha_{n} \gamma V_{3}\left(z_{n}\right)+\left(I_{1}-\mu \alpha_{n} F_{3}\right) \sum_{k=1}^{s} \omega_{k}\left(I_{1}-\frac{1}{\left\|B_{2}\right\|^{2}} B_{2}^{*}\left(I_{1}-P_{E_{k}}\right) B_{2}\right)\left(z_{n}-\frac{\xi}{3}\left(2 z_{n}-x_{n}-y_{n}\right)\right)$ for all $n \in \mathbb{N}$.

Then $\lim _{n \rightarrow \infty}\left(x_{n}, y_{n}, z_{n}\right) \in V I(\mu F-\gamma V, \Lambda)$.

Proof. For each $k \in\{1,2, \ldots, s\}$, let $G_{3 k}=P_{E_{k}}$. Since $P_{E_{k}}$ is a firmly nonexpansive mapping, $P_{E_{k}}$ is averaged and $P_{E_{k}}$ is demiclosed. By Proposition 2.2, $G_{k}$ is a $\delta_{k}$-strongly quasi-nonexpansive mapping for some $\delta_{k}>0$. Hence $G_{k}$ is a $\delta_{k}$-demicontractive mapping for some $\delta_{k}>0$. Then Corollary 4.10 follows from Theorem 4.8 .

Theorem 4.11. Let $\left(\zeta_{1}, \zeta_{2}, \ldots, \zeta_{m}\right) \in \Delta_{m},\left(\theta_{1}, \theta_{2}, \ldots, \theta_{\ell}\right) \in \Delta_{\ell},\left(\omega_{1}, \omega_{2}, \ldots, \omega_{s}\right) \in \Delta_{s}$, let $V_{i}: H_{1} \rightarrow H_{1}$ be $\mathrm{L}_{i}$-Lipschitz continuous, $\mathrm{F}_{i}: \mathrm{H}_{1} \rightarrow \mathrm{H}_{1}$ be $\mathrm{K}_{i}$-Lipschitz continuous and $\eta_{i}$-strongly monotone with $\mathrm{K}_{i}>0$, and $\eta_{i}>0$ and let $\mathrm{k}>0$. Suppose that

$$
\begin{gathered}
\Lambda=\left\{(x, x, x): x \in H_{1}, x \in \bigcap_{i=1}^{m} \arg \min _{u \in H_{1}}\left(h_{1 i}+g_{1 i}(u)\right), B_{1}(x) \in \bigcap_{j=1}^{\ell} \arg \min _{u \in H_{2}}\left(h_{2 j}+g_{2 j}\right)(u),\right. \\
\left.B_{2}(x) \in \bigcap_{k=1}^{s} \operatorname{Fix}\left(G_{k}\right)\right\} \neq \emptyset .
\end{gathered}
$$

Let $x_{1} \in H_{1}, y_{1} \in H_{1}, z_{1} \in H_{1}$, and let the sequences $\left\{\left(x_{n}, y_{n}, z_{n}\right)\right\}_{n \in \mathbb{N}}$ be defined by

(i) $x_{n+1}=\alpha_{n} \gamma V_{1}\left(x_{n}\right)+\left(I_{1}-\mu \alpha_{n} F_{1}\right) \sum_{i=1}^{m} \zeta_{i} \operatorname{prox}_{k h_{1 i}}\left(I_{1}-\kappa \nabla g_{1 i}\right)\left(x_{n}-\frac{\xi}{3}\left(2 x_{n}-y_{n}-z_{n}\right)\right)$ for all $n \in \mathbb{N}$;

(ii) $y_{n+1}=\alpha_{n} \gamma V_{2}\left(y_{n}\right)+\left(I_{1}-\mu \alpha_{n} F_{2}\right) \sum_{j=1}^{\ell} \theta_{j}\left(I_{1}-\frac{1}{\left\|B_{1}\right\|^{2}} B_{1}^{*}\left(I_{2}-\left(\operatorname{prox}_{\kappa h_{2 j}}\left(I_{2}-\kappa \nabla g_{2 j}\right)\right) B_{1}\right)\right)\left(y_{n}-\frac{\xi}{3}\left(y_{n}-\right.\right.$ $\left.x_{n}-z_{n}\right)$ ) for all $n \in \mathbb{N}$;

(iii) $z_{n+1}=\alpha_{n} \gamma V_{3}\left(z_{n}\right)+\left(I_{1}-\mu \alpha_{n} F_{3}\right) \sum_{k=1}^{s} \omega_{k}\left(I_{1}-\frac{1}{\left\|B_{2}\right\|^{2}} B_{2}^{*}\left(I_{3}-G_{k \eta_{k}}\right) B_{2}\right)\left(z_{n}-\frac{\xi}{3}\left(2 z_{n}-x_{n}-y_{n}\right)\right)$ for all $n \in \mathbb{N}$.

Then $\lim _{n \rightarrow \infty}\left(x_{n}, y_{n}, z_{n}\right) \in V I(\mu F-\gamma V, \Lambda)$.

Proof. Apply Lemma 2.3 and argue as the proof II of [25, Theorem 4.2], we see that for each $i \in$ $\{1,2, \ldots, m\}, j \in\{1,2, \ldots, l\}$,

(i) $\partial h_{i}, \partial h_{j}^{\prime}$ are maximum monotone operator;

(ii) $\nabla g_{1 i}$ is a $\frac{1}{\sigma_{1 i}}$-inverse strongly monotone operator, $\nabla g_{2 j}$ is a $\frac{1}{\sigma_{2 j}}$-inverse strongly monotone operator;

(iii) $\operatorname{prox}_{\kappa h_{1 i}}\left(I_{1}-\kappa \nabla g_{1 i}\right)=J_{\kappa}^{\partial h_{1 i}}\left(I_{1}-\kappa \nabla g_{1 i}\right), \operatorname{prox}_{\kappa h_{2 j}}\left(I_{1}-\kappa \nabla g_{2 j}\right)=J_{\kappa}^{\partial h_{2 j}}\left(I_{1}-\kappa \nabla g_{2 j}\right)$;

(iv) $\arg \min _{x \in H_{1}}\left(h_{1 i}+g_{1 i}\right)(x)=\left(\partial h_{1 i}+\nabla g_{1 i}\right)^{-1} 0, \arg \min _{x \in H_{2}}\left(h_{2 j}+g_{2 j}\right)(x)=\left(\partial h_{2 j}+\nabla g_{2 j}\right)^{-1} 0$.

Then Theorem 4.11 follows from Theorem 4.2.

Remark 4.12. Since a strictly pseudo-contractive mapping is a demi-contractive mapping. It is easy to see that Theorem 4.11 extends [4, Theorem 2.9].

Theorem 4.13. Let $\left(\zeta_{1}, \zeta_{2}, \ldots, \zeta_{\mathrm{m}}\right) \in \Delta_{\mathrm{m}},\left(\theta_{1}, \theta_{2}, \ldots, \theta_{\ell}\right) \in \Delta_{\ell},\left(\omega_{1}, \omega_{2}, \ldots, \omega_{s}\right) \in \Delta_{s}$, let $\mathrm{V}_{\mathrm{i}}: \mathrm{H}_{1} \rightarrow \mathrm{H}_{1}$ be $\mathrm{L}_{\mathrm{i}}$-Lipschitz continuous, $\mathrm{F}_{\mathrm{i}}: \mathrm{H}_{1} \rightarrow \mathrm{H}_{1}$ be $\mathrm{K}_{\mathrm{i}}$-Lipschitz continuous and $\eta_{\mathrm{i}}$-strongly monotone with $\mathrm{K}_{\mathrm{i}}>0$, and $\eta_{i}>0$ and let $\mathrm{k}>0$. Suppose that

$$
\begin{gathered}
\Lambda=\left\{(x, x, x): x \in H_{1}, x \in \bigcap_{i=1}^{m} \arg \min _{u \in H_{1}}\left(h_{1 i}+g_{1 i}(u)\right), B_{1}(x) \in \bigcap_{j=1}^{\ell} \arg \min _{y \in H_{2}}\left(h_{2 j}+g_{2 j}\right)(y),\right. \\
\left.B_{2}(x) \in \bigcap_{k=1}^{s} \arg \min _{z \in H_{3}}\left(h_{3 k}+g_{3 k}\right)(z)\right\} \neq \emptyset .
\end{gathered}
$$

Let $x_{1} \in H_{1}, y_{1} \in H_{1}, z_{1} \in H_{1}$, and let the sequences $\left\{\left(x_{n}, y_{n}, z_{n}\right)\right\}_{\mathfrak{n} \in \mathbb{N}}$ be defined by 
(i) $x_{n+1}=\alpha_{n} \gamma V_{1}\left(x_{n}\right)+\left(I_{1}-\mu \alpha_{n} F_{1}\right) \sum_{i=1}^{m} \zeta_{i} \operatorname{prox}_{k h_{1 i}}\left(I_{1}-k \nabla g_{1 i}\right)\left(x_{n}-\frac{\xi}{3}\left(2 x_{n}-y_{n}-z_{n}\right)\right)$ for all $n \in \mathbb{N}$;

(ii) $y_{n+1}=\alpha_{n} \gamma V_{2}\left(y_{n}\right)+\left(I_{1}-\mu \alpha_{n} F_{2}\right) \sum_{j=1}^{\ell} \theta_{j}\left(I_{1}-\frac{1}{\left\|B_{1}\right\|^{2}} B_{1}^{*}\left(I_{2}-\operatorname{prox}_{\kappa h_{2 j}}\left(I_{2}-\kappa \nabla g_{2 j}\right) B_{1}\right)\right)\left(y_{n}-\frac{\xi}{3}\left(y_{n}-\right.\right.$ $\left.x_{n}-z_{n}\right)$ ) for all $n \in \mathbb{N}$;

(iii) $z_{n+1}=\alpha_{n} \gamma V_{3}\left(z_{n}\right)+\left(I_{1}-\mu \alpha_{n} F_{3}\right) \sum_{k=1}^{s} \omega_{k}\left(I_{1}-\frac{1}{\left\|B_{2}\right\|^{2}} B_{2}^{*}\left(I_{3}-\operatorname{prox}_{k h_{3 k}}\left(I_{3}-\kappa \nabla g_{3 k}\right) B_{2}\right)\right)\left(z_{n}-\frac{\xi}{3}\left(2 z_{n}-\right.\right.$ $x_{n}-y_{n}$ )) for all $n \in \mathbb{N}$.

Then $\lim _{n \rightarrow \infty}\left(x_{n}, y_{n}, z_{n}\right) \in V I(\mu F-\gamma V, \Lambda)$.

Proof. For each $k \in\{1,2, \ldots, s\}$, let $G_{k}=\operatorname{prox}_{k h_{3 k}}\left(I_{2}-k \nabla g_{3 k}\right)$. We show in Theorems 4.1 and 4.11 that

(i) $\operatorname{prox}_{\mathrm{kh}}\left(\mathrm{I}_{1}-\mathrm{k} \nabla \mathrm{g}_{3 \mathrm{k}}\right)=\mathrm{J}_{\mathrm{k}}^{\partial \mathrm{h}_{3 \mathrm{k}}}\left(\mathrm{I}_{1}-\mathrm{k} \nabla \mathrm{g}_{3 \mathrm{k}}\right)$;

(ii) $\arg \min _{x \in H_{1}}\left(h_{3 k}+g_{3 k}\right)(x)=\left(\partial h_{3 k}+\nabla g_{3 k}\right)^{-1} 0$;

(iii) $\mathrm{J}_{\mathrm{K}}^{\partial h_{3 k}}\left(\mathrm{I}_{1}-\mathrm{k} \nabla \mathrm{g}_{3 \mathrm{k}}\right)$ is a $\delta_{\mathrm{k}}$-strongly quasi-nonexpansive mapping for some $\delta_{k}>0$.

Then Theorem 4.13 follows from Theorem 4.4.

Corollary 4.14. In Theorem 4.13, let $\mathrm{H}_{1}=\mathrm{H}_{2}=\mathrm{H}_{3}=\mathrm{H}_{4}, \mathrm{I}_{1}=\mathrm{I}_{2}=\mathrm{I}_{3}$, and $\left(\zeta_{1}, \zeta_{2}, \ldots, \zeta_{\mathrm{m}}\right) \in \Delta_{\mathrm{m}},\left(\theta_{1}, \theta_{2}, \ldots, \theta_{\ell}\right) \in$ $\Delta_{\ell},\left(\omega_{1}, \omega_{2}, \ldots, \omega_{s}\right) \in \Delta_{s}, k>0$. Suppose that

$$
\Lambda=\left\{(x, x, x): x \in H_{1}, x \in \bigcap_{i=1}^{m} \arg \min _{u \in H_{1}}\left(h_{1 i}+g_{1 i}(u)\right) \bigcap \bigcap_{j=1}^{\ell} \arg \min _{y \in H_{2}}\left(h_{2 j}+g_{2 j}\right)(y) \bigcap \bigcap_{k=1}^{s} \arg \min _{z \in H_{3}}\left(h_{3 k}+g_{3 k}\right)(z)\right\}
$$
$\neq \emptyset$.

Let $\mathrm{x}_{1} \in \mathrm{H}_{1}, \mathrm{y}_{1} \in \mathrm{H}_{1}, z_{1} \in \mathrm{H}_{1}$, and let the sequences $\left\{\left(\mathrm{x}_{\mathrm{n}}, \mathrm{y}_{\mathrm{n}}, \mathrm{z}_{\mathrm{n}}\right)\right\}_{\mathfrak{n} \in \mathbb{N}}$ be defined by

(i) $x_{n+1}=\alpha_{n} \gamma V_{1}\left(x_{n}\right)+\left(I_{1}-\mu \alpha_{n} F_{1}\right) \sum_{i=1}^{m} \zeta_{i} \operatorname{prox}_{\kappa h_{1 i}}\left(I_{1}-\kappa \nabla g_{1 i}\right)\left(x_{n}-\frac{\xi}{3}\left(2 x_{n}-y_{n}-z_{n}\right)\right)$ for all $n \in \mathbb{N}$;

(ii) $y_{n+1}=\alpha_{n} \gamma V_{2}\left(y_{n}\right)+\left(I_{1}-\mu \alpha_{n} F_{2}\right) \sum_{j=1}^{\ell} \theta_{j}\left(I_{2}-\operatorname{prox}_{k h_{2 j}}\left(I_{2}-\kappa \nabla g_{2 j}\right)\left(y_{n}-\frac{\xi}{3}\left(y_{n}-x_{n}-z_{n}\right)\right)\right.$ for all $\mathrm{n} \in \mathbb{N}$;

(iii) $z_{n+1}=\alpha_{n} \gamma V_{3}\left(z_{n}\right)+\left(I_{1}-\mu \alpha_{n} F_{3}\right) \sum_{k=1}^{s} \omega_{k}\left(I_{3}-\operatorname{prox}_{k h_{3 k}}\left(I_{2}-k \nabla g_{3 k}\right)\left(z_{n}-\frac{\xi}{3}\left(2 z_{n}-x_{n}-y_{n}\right)\right)\right.$ for all $n \in \mathbb{N}$.

Then $\lim _{n \rightarrow \infty}\left(x_{n}, y_{n}, z_{n}\right) \in V I(\mu F-\gamma V, \Lambda)$.

Proof. Let $\mathrm{B}_{1}=\mathrm{I}_{1}=\mathrm{B}_{2}$ in Theorem 4.13, then Corollary 4.14 follows from Theorem 4.13.

Remark 4.15. Corollaries 3.4, 3.12, 4.7, 4.10, and 4.14 have real applications in the large scale of nonlinear problems and optimization problems. Indeed if the scale of nonlinear problems is large, we can group these problems into finite families of nonlinear problems, then we use simultaneous iteration to find the solutions of these problems.

Theorem 4.16. For each $i \in\{1,2, \ldots, m\}, j \in\{1,2, \ldots, \ell\}, k \in\{1,2, \ldots, s\}$, let $k>0$, let

(i) $f_{i}: C_{i} \times C_{i} \rightarrow \mathbb{R}$ be a bifunction which satisfies conditions (A1)-(A4);

(ii) $\mathrm{Q}_{\mathrm{j}}: \mathrm{H}_{2} \rightarrow \mathrm{H}_{2}$ be a hemicontinuous, locally bounded monotone mapping;

(iii) $\mathrm{h}_{3 \mathrm{k}} \in \Gamma_{0}\left(\mathrm{H}_{3}\right), \mathrm{g}_{3 \mathrm{k}} \in \Gamma_{0}\left(\mathrm{H}_{3}\right), \mathrm{g}_{3 \mathrm{k}}$ be Fréchet differentiable with $\sigma_{3 \mathrm{k}}$-Lipschitz continuous Fréchet derivative $\nabla g_{3 k}$.

For $\mathrm{r}>0, \mathrm{x} \in \mathrm{H}_{1}$, and $\mathrm{u} \in \mathrm{H}_{2}$, let

(i) $\mathrm{M}_{\mathrm{i}}: \mathrm{H}_{1} \rightarrow \mathrm{C}_{\mathrm{i}}$ be defined by $\mathrm{M}_{\mathrm{i}}(\mathrm{x})=\left\{z \in \mathrm{C}_{\mathrm{i}}: \mathrm{f}_{\mathrm{i}}(z, \mathrm{u})+\frac{1}{\mathrm{r}}\langle\mathrm{u}-z, z-x\rangle \geqslant 0, \forall u \in \mathrm{C}_{\mathrm{i}}\right\}$;

(ii) $\mathrm{P}_{\mathrm{j}}: \mathrm{H}_{2} \rightarrow \mathrm{D}_{\mathrm{j}}$ be defined by $\mathrm{P}_{\mathrm{j}}(\mathrm{u})=\left\{z \in \mathrm{D}_{\mathrm{j}}:\left\langle\mathrm{y}-z, \mathrm{Q}_{\mathrm{j}}(z)\right\rangle+\frac{1}{\mathrm{r}}\langle\mathrm{y}-z, z-\mathrm{u}\rangle \geqslant 0, \forall \mathrm{y} \in \mathrm{D}_{\mathrm{j}}\right\}$. 
Let $\left(\zeta_{1}, \zeta_{2}, \ldots, \zeta_{m}\right) \in \Delta_{m},\left(\theta_{1}, \theta_{2}, \ldots, \theta_{\ell}\right) \in \Delta_{\ell},\left(\omega_{1}, \omega_{2}, \ldots, \omega_{s}\right) \in \Delta_{s}, \eta>0$. Suppose that

$$
\begin{aligned}
& \Lambda=\{(x, y, z) \in \bigotimes_{1 \leqslant i \leqslant 3} H_{i}: x \in \bigcap_{i=1}^{m} E P\left(f_{i}\right), y \in \bigcap_{j=1}^{\ell} V I\left(Q_{j}, D_{j}\right), z \in \bigcap_{k=1}^{s} \arg \min _{w \in H_{3}}\left(h_{3 k}+g_{3 k}\right)(w), \\
&\left.A_{1}(x)=A_{2}(y)=A_{3}(z)\right\} \neq \emptyset .
\end{aligned}
$$

Let $x_{1} \in \mathrm{H}_{1}, \mathrm{y}_{1} \in \mathrm{H}_{2}, z_{1} \in \mathrm{H}_{3}$, and let the sequences $\left\{\left(x_{n}, y_{n}, z_{n}\right)\right\}_{n} \in \mathbb{N}$ be defined by

(i) $x_{n+1}=\alpha_{n} \gamma V_{1}\left(x_{n}\right)+\left(I_{1}-\mu \alpha_{n} F_{1}\right) \sum_{i=1}^{m} \zeta_{i} M_{i}\left(x_{n}-\frac{\xi}{3} A_{1}^{*}\left(2 A_{1}\left(x_{n}\right)-A_{2}\left(y_{n}\right)-A_{3}\left(z_{n}\right)\right)\right)$ for all $n \in \mathbb{N}$;

(ii) $y_{n+1}=\alpha_{n} \gamma V_{2}\left(y_{n}\right)+\left(I_{2}-\mu \alpha_{n} F_{2}\right) \sum_{j=1}^{\ell} \theta_{j} P_{j}\left(y_{n}-\frac{\xi}{3} A_{2}^{*}\left(2 A_{2}\left(y_{n}\right)-A_{1}\left(x_{n}\right)-A_{3}\left(z_{n}\right)\right)\right)$ for all $n \in \mathbb{N}$;

(iii) $z_{n+1}=\alpha_{n} \gamma V_{3}\left(z_{n}\right)+\left(I_{3}-\mu \alpha_{n} F_{3}\right) \sum_{k=1}^{s} \omega_{k}\left(I_{3}-\operatorname{prox}_{k h_{3 k}}\left(I_{3}-k \nabla g_{3 k}\right)\left(z_{n}-\frac{\xi}{3} A_{3}^{*}\left(2 A_{3}\left(z_{n}\right)-A_{1}\left(x_{n}\right)-\right.\right.\right.$ $\left.\mathrm{A}_{2}\left(\mathrm{y}_{\mathrm{n}}\right)\right)$ ) for all $\mathrm{n} \in \mathbb{N}$.

Then $\lim _{n \rightarrow \infty}\left(x_{n}, y_{n}, z_{n}\right) \in V I(\mu F-\gamma V, \Lambda)$.

Proof. It follows from Theorem 2.5 that for each $i \in\{1,2, \ldots, m\}$,

(i) $M_{i}$ is single-valued;

(ii) $M_{i}$ is firmly nonexpansive;

(iii) $\left\{x \in \mathrm{H}_{1}: M_{i} x=x\right\}=\left\{x \in C_{i}: f_{i}(x, u) \geqslant 0, \forall u \in C_{i}\right\}$.

By Theorem 2.6,

(i) $P_{j}$ is single-valued;

(ii) $P_{j}$ is a firmly nonexpansive mapping;

(iii) $\left\{x \in H: P_{j} x=x\right\}=V I\left(Q_{j}, D_{j}\right)$.

As in the proof of Theorem 3.18, we see that

(i) $M_{i}$ is a $\lambda_{i}$-strongly quasi-nonexpansive mapping for some $\lambda_{i}>0$;

(ii) $P_{j}$ is a demiclosed $\beta_{j}$-strongly quasi-nonexpansive mapping for some $\beta_{j}>0$.

We show in Theorems 4.13 that

(i) $\operatorname{prox}_{\kappa h_{3 k}}\left(\mathrm{I}_{1}-\mathrm{k} \nabla \mathrm{g}_{3 \mathrm{k}}\right)=\mathrm{J}_{\mathrm{k}}^{\partial \mathrm{h}_{3 \mathrm{k}}}\left(\mathrm{I}_{1}-\mathrm{k} \nabla \mathrm{g}_{3 \mathrm{k}}\right)$;

(ii) $\arg \min _{x \in H_{1}}\left(h_{3 k}+g_{3 k}\right)(x)=\left(\partial h_{3 k}+\nabla g_{3 k}\right)^{-1} 0$;

(iii) $J_{k}^{\partial h_{3 k}}\left(I_{1}-k \nabla g_{3 k}\right)$ is a $\delta_{k}$-strongly quasi-nonexpansive mapping for some $\delta_{k}>0$.

Then Theorem 4.16 follows from Theorem 3.3.

\section{Acknowledgment}

This work was supported by National Changhua University of Education. The author is grateful to the referees for their valuable suggestions during the preparation of this paper.

\section{References}

[1] H. H. Bauschke, P. L. Combettes, Convex analysis and monotone operator theory in Hilbert spaces, Springer, New York, (2011). 2.2, 2.10, 2.12

[2] E. Blum, W. Oettli, From optimization and variational inequalities, Math. Student, 63 (1994), 123-146. 2

[3] F. E. Browder, Fixed point theorems for noncompact mappings in Hilbert spaces, Proc. Nat. Acad. Sci. U.S.A., 53 (1965), 1272-1276. 2.1

[4] G. Cai, Y. Shehu, An iteration for fixed point problem and convex minimization problems with applications, Fixed Point Theory Appl., 2015 (2015), 17 pages. 4.9, 4.12 
[5] A. Cegielski, General methods for solving the split common fixed point problem, J. Optim. Theory Appl., 165 (2015), 385-404. 2.8, 2.9, 3.8

[6] Y. Censor, T. Elfving, A multiprojection algorithm using Bregman projection in a product space, Numer. Algorithms, 8 (1994), 221-239. 1

[7] Y. Censor, A. Segal, The split common fixed point problem for directed operators, J. Convex Anal., 16 (2009), 587-600. 1

[8] S.-S. Chang, L. Wang, Y. K. Tang, G. Wang, Moudafi's open question and simultaneous iterative algorithm for general split equality variational inclusion problems and general split equality optimization problem, Fixed Point Theory Appl., 2014 (2014), 17 pages. 1

[9] S.-S. Chang, L. Wang, L.-J. Qin, Split equality fixed point problem for quasi-pseudo-contractive mappings with applications, Fixed Point Theory Appl., 2015 (2015), 12 pages. 2.11, 3.17

[10] H. Che, M. Li, A simultaneous iteration methods for split equality problems of two finite families of strictly pseudononspreading mappings without prior knowledge of operator norms, Fixed Point Theory Appl., 2015 (2015), 14 pages. 1, 3.10

[11] C.-S. Chuang, L.-J. Lin, Z.-T. Yu, Mathematical programming over the solution set of the minimization problem for the sum of two convex functions, J. Nonlinear Convex Anal., 17 (2016), 2105-2118. 1

[12] P. L. Combettes, S. A. Hirstoaga, Equilibrium programming in Hilbert spaces, J. Nonlinear Convex Anal., 6 (2005), 117-136. 2.5

[13] M. Eslamian, P. Eslamian, Strong convergence of split common fixed point problem, Numer. Funct. Anal. Optim., 37 (2016), 1248-1266. 3.8

[14] G. M. Lee, L.-J. Lin, Variational inequalities over split equality fixed point sets of strongly quasi-nonexpansive mappings, J. Nonlinear Convex Anal., 18 (2017), 1781-1800. 1, 2.6, 2.7, 3.1, 3.2, 3.6, 3.10

[15] P.-E. Maingé, Strong convergence of projected subgradient methods for nonsmooth and nonstrictly convex minimization, Set-Valued Anal., 16 (2008), 899-912. 2.3

[16] G. Marino, H.-K. Xu, Weak and strong convergence theorems for strict pseudo-contraction in Hilbert spaces, J. Math. Anal. Appl., 329 (2007), 336-346. 2.13

[17] A. Moudafi, A note on the split common fixed point problem for quasi-nonexpansive operators, Nonlinear Anal., 74 (2011), 4083-4087. 1

[18] A. Moudafi, A relaxed alternating CQ-algorithm for convex feasibility problems, Nonlinear Anal., 79 (2013), 117-121. 1

[19] A. Moudafi, E. AI-Shemas, Simultaneous iterative methodsfor split equality problems, Trans. Math. Program Appl., 2013 (2013), 10 pages. 1

[20] M. O. Osilike, F. O. Isiogugu, Weak and strong convergence theorems for nonspreading-type mappings in Hilbert spaces, Nonlinear Anal., 74 (2011), 1814-1822. 2, 2.4

[21] W. Takahashi, H.-K. Xu, J.-C. Yao, Iterative methods for generalized split feasibility problems in Hilbert spaces, Set-Valued Var. Anal., 23 (2015), 205-221. 4.3

[22] Y. Wang, X. Fang, Viscosity approximation for the multiple -set split equality fixed point problem of demicontractive mappings, J. Nonlinear Sci. Appl., 10 (2017), 4254-4268. 3.6

[23] Y. Wang, T. H. Kim, Simultaneous iterative algorithm for the split equality fixed point problem of demicontractive mappings, J. Nonlinear Sci. Appl., 10 (2017), 154-165. 1, 4.6

[24] Y. Wang, T.-H. Kim, X. Fang, H. He, The split common fixed point for demicontractive mappings and quasi-nonexpansive mappings, J. Nonlinear Sci. Appl., 10 (2017), 2976-2985. 1, 3.6, 3.20

[25] Z.-T. Yu, L.-J. Lin, C.-S. Chuang, Mathematical programing with multiple sets split monotone variational inclusion constraints, Fixed Point Theory Appl., 2014 (2014), 27 pages. 4, 4

[26] J. Zhao, S. N. He, Simultaneous iterative algorithm for the split common fixed point problem governed by quasinonexpansive mappings, J. Nonlinear and Convex Anal., (accepted). 1

[27] J. Zhao, S. Wang, Viscosity approximate methods for trhe split equality quasi-nonexpansive operators, Acta Math. Sci. Ser. B Engl. Ed., 36 (2016), 1474-1486. 1, 3.8 